\title{
Intelligent Control of Smooth Blasting Quality in Rock Tunnels Using BP-ANN, ENN, and ANFIS
}

\author{
Baoping Zou $\mathbb{D}^{1,2}$ Jianxiu Wang $\mathbb{D}^{2},{ }^{2}$ Zhanyou Luo $\mathbb{D}^{1},{ }^{1}$ and Lisheng $\mathrm{Hu} \mathbb{D}^{3}$ \\ ${ }^{1}$ School of Civil Engineering and Architecture, Zhejiang University of Science and Technology, Hangzhou 310023, China \\ ${ }^{2}$ Department of Geotechnical Engineering, Tongji University, Shanghai 200092, China \\ ${ }^{3}$ China Railway No.2 Engineering Group Co., Ltd, Chengdu 610031, China
}

Correspondence should be addressed to Baoping Zou; zoubp@zust.edu.cn

Received 15 December 2020; Revised 5 January 2021; Accepted 12 January 2021; Published 27 January 2021

Academic Editor: Feng Xiong

Copyright (C) 2021 Baoping Zou et al. This is an open access article distributed under the Creative Commons Attribution License, which permits unrestricted use, distribution, and reproduction in any medium, provided the original work is properly cited.

The construction quality of tunnel smooth blasting is difficult to control and fluctuates greatly. Moreover, the existing technology, which relies on the visual observation, empirical judgment, and artificial control, has difficulty meeting the requirements of tunnel smooth blasting construction quality control. This paper presents the construction principle of a tunnel smooth blasting quality control system, introduces a process quality control technology into quality control of tunnel smooth blasting construction, designs a framework for the tunnel smooth blasting quality control system, and collects control index data based on field investigation, expert consultation, and experimental research. By using the methods of index utilization rate statistics, gray correlation analysis, and principal component analysis, this paper primarily elects and selects the control indexes; establishes the tunnel smooth blasting quality control index system; constructs a comprehensive optimization control model of tunnel smooth blasting quality using back propagation artificial neural network (BP-ANN), Elman neural network (ENN), and adaptive neuro fuzzy inference systems (ANFIS); and studies the tunnel smooth blasting quality control system. The following are the conclusions of this study: (1) This paper presented a method of constructing a tunnel smooth blasting quality control index system and established this system with seven criteria layers, namely, geological conditions, explosive properties, borehole parameters, charge parameters, method of initiation, tunnel parameters, and construction factors, as well as a total of nine indexes. (2) The comprehensive optimization control model of BP-ANN, ANFIS, and ENN for tunnel smooth blasting quality was established. (3) The uniform design method was used to optimize the blasting parameters of the tunnel section, which needs to be controlled, and verify that the construction of these comprehensive optimization control models can change the focus of tunnel smooth blasting quality control from the traditional single index control method into a dynamic, intelligent, pluralistic, and integrated control technology.

\section{Introduction}

Tunnel smooth blasting quality control is a general term in engineering practice in which the construction side of the employer, the construction side of the contractor, and other participating units identify, assess, and prevent all problems at all stages of the tunnel engineering blasting construction and control the whole process, work through the tunnel blasting construction through professional technology and construction management work, and obtain optimal economic benefits and safety guarantee with minimum engineering cost. The tunnel smooth blasting construction process is complex. After blasting, the unlined tunnel molding must be regular and has a smooth surface. The molded contour outside the rock is not subject to artillery disturbance and destruction. The contour inside the rock should be well broken, with high requirements for construction accuracy. However, given the many factors that influence the tunnel smooth blasting quality, the tunnel smooth blasting construction quality is difficult to control and fluctuates greatly. In ensuring the construction quality of tunnel smooth blasting control, the existing technology, which relies on the method of visual observation, empirical judgment, and artificial control, has difficulty meeting the requirements of tunnel 
smooth blasting construction quality control. To ensure the quality of tunnel smooth blasting construction, the focus of quality control should change from the traditional single index control method to a dynamic, intelligent, pluralistic, and integrated control technology.

Many factors influence the quality of tunnel smooth blasting, which is difficult to control and fluctuates greatly. Determining how to control the quality of tunnel smooth blasting correctly and reasonably has attracted the attention of researchers at home and abroad, and many promising studies have been conducted on the subject. Research on tunnel smooth blasting quality control in China has obtained productive results, such as the Railway Tunnel Construction Specifications, the Railway Tunnel Construction Technical Guide, and the Highway Tunnel Construction Technical Specifications. All these guidelines provide a control index for tunnel smooth blasting. However, the proposed control index does not form a system, the actual smooth blasting control process is greatly influenced by human subjectivity, and the accuracy and reliability of the control is poor. Numerous domestic scholars have also conducted extensive research on the tunnel smooth blasting quality control, which mainly involves the repeated test and optimization of blasting parameters [1-12], neural network models [13, 14], mutation comprehensive evaluation theory [15], computer simulation [16, 17], information construction $[18,19]$, three-dimensional laser scanning [20], and other technologies, thereby proposing a reasonable control technology. However, no unified system exists for studying the tunnel smooth blasting control index, control criterion, and control method. Moreover, the scholars did not present a quantitative grading and classification, provided no control on the whole process of tunnel smooth blasting construction, and did not develop a dynamic, intelligent, pluralistic, and integrated tunnel smooth blasting quality control technology.

Therefore, the following steps are necessary: process quality control technology needs to be introduced into tunnel smooth blasting construction quality control, a set of tunnel smooth blasting quality control index system should be established, a tunnel smooth blasting quality control model must be constructed, and the quality of tunnel smooth blasting should be ensured by focusing on controlling the quality of the tunnel smooth blasting construction process. Thus, in accordance with the evaluation level of tunnel smooth blasting quality, tunnel smooth blasting parameters are optimized and adjusted, with the postcontrol of smooth blasting quality being changed to precontrol, which is beneficial to the construction side of the employer, the construction side of the contractor, and other participating units in formulating the appropriate control range for the key links of tunnel smooth blasting construction and to monitor and effectively control it in real time.

\section{Materials and Methods}

\subsection{Principle of the Model}

2.1.1. Back Propagation Artificial Neural Network (BP-ANN). A back propagation artificial neural network (BP-ANN), one

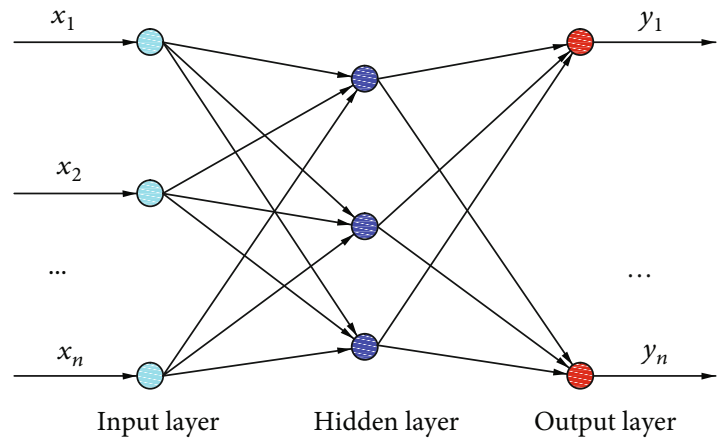

Figure 1: The structure of the BP-ANN.

of the most popular neural network algorithms, processes information by imitating the structure and function of the human central nervous system [21]. The structure of a BPANN is shown in Figure 1.

Each node in the network is a neuron whose function is to calculate the inner product of the input vector and weight vector by a nonlinear transfer function to get a scalar result. This particular network is a three-layer network: the input layer, the hidden layer, and the output layer. The mathematical model $[21,22]$ of the three-layer BP-ANN is expressed as the output of the hidden layer neurons for:

$$
H_{j}=f\left(\sum_{i=1}^{n} w_{i j} x_{i}-a_{j}\right) \quad j=1,2, \cdots l,
$$

where $H_{j}$ and $x_{i}$ are the output values of the hidden layer and input value of the network, respectively. $n$ and $l$ are the numbers of input and hidden layer neurons. Respectively, $i, k$, and $w_{i j}$ are the input neurons, hidden neurons, and weighting of inputs to the hidden layer neuron. $a_{j}$ denotes the threshold of the hidden layer neurons. $f$ is the activation function of a node.

The output of the output layer neurons is expressed as:

$$
y_{j}=f\left(\sum_{k=1}^{l} w_{k j} H_{k}-b_{j}\right) \quad j=1,2, \cdots m,
$$

where $y_{j}$ and $H_{k}$ are the actual output values of the output layer and the output values of the hidden layer, respectively. $l$ and $m$ are the numbers of hidden and output layer neurons. Respectively, $k, j$, and $w_{k j}$ represent the hidden neurons, output neurons, and the weighting of the hidden neurons to the output layer neurons. $b_{j}$ denotes the threshold of the output layer neurons.

Minimize the global error $E$ via the training algorithm is expressed as:

$$
E=\frac{1}{2} \sum\left(y_{j}-R_{t}\right)^{2}
$$

where $R_{t}$ is the real output of training data. 


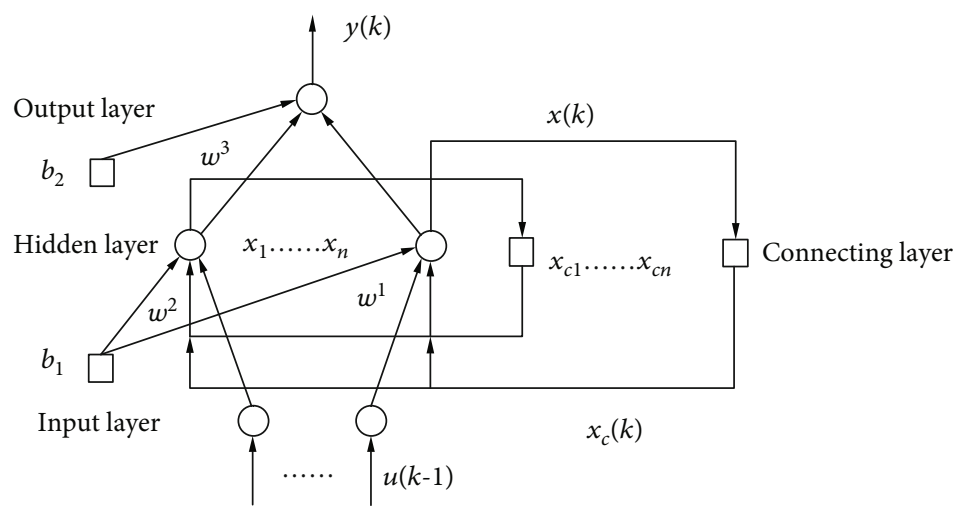

FIgURE 2: The structure of the ENN.

2.1.2. Elman Neural Network (ENN). Elman neural network (ENN) is a local-feedback recursive neural network, which belongs to a nonlinear state space model. The ENN includes 4 main layers: the input layer, the context layer, the hidden layer, and the output layer. The function of the connecting layer is to receive the output of the hidden layer and transmit the information corresponding to the previous time to the hidden layer in the form of feedback to establish a local ring structure. As the connecting layer unit has a delayed memory effect on the characteristics contained in historical data, the output value of the neural network is more in line with the actual development trend of data $[23,24]$. The ENN structure is shown in Figure 2.

State space equation of ENN [23] is shown in Eqs. (4)-(6):

$$
\begin{aligned}
x(k) & =f\left(w^{1} x_{c}(k)+w^{2}(u(k-1))+b_{1}\right), \\
y(k) & =g\left(w^{3} x(k)+b_{2}\right), \\
x_{c}(k) & =x(k-1),
\end{aligned}
$$

where $x(k)$ and $x_{c}(k)$ represent output vectors of hidden layer and connecting layer at time $k$, respectively, $u(k-1)$ is input layer vector at time $k-1$, and $y(k)$ is output vector at time $k . w^{1}$ denotes the weight vectors $\theta$ between hidden layer and hidden layer, $w^{2}$ denotes the weight vectors between input layer and hidden layer, and $w^{3}$ denotes the weights matrix between hidden layer and output layer. $b_{1}$ and $b_{2}$ are threshold vectors $\varphi$ of hidden layer and output layer, respectively. $f(\cdot)$ and $g(\cdot)$ represent the transfer function of neurons in hidden layer and output layer, respectively.

The weights of ENN are adjusted by minimizing the RMSE (root mean square error), which is estimated by Eq. (7):

$$
\mathrm{RMSE}=\sqrt{\frac{1}{M-1} \sum_{n=1}^{M}\left[y(k)-y_{e}(k)\right]^{2}},
$$

where $y_{e}(k)$ denotes the expected value at time $k$ and $M$ is total time.
2.1.3. Adaptive Neuro Fuzzy Inference Systems (ANFIS). The adaptive neuro fuzzy inference system (ANFIS) is a fuzzy Sugeno model entered in the framework of adaptive systems to facilitate learning and adaptation. To present the ANFIS architecture $[25,26]$, two fuzzy if-then rules based on a first-order Sugeno model are considered:

$$
\text { Rule } 1 \text { : if } x \text { is } A_{1} \text { and } y \text { is } B_{1} \text {, then } f_{1}=p_{1} x+q_{1} y+r_{1} \text {, }
$$

Rule $2:$ if $x$ is $A_{2}$ and $y$ is $B_{2}$, then $f_{2}=p_{2} x+q_{2} y+r_{2}$,

where $x$ and $y$ are the inputs, $A_{i}$ and $B_{i}$ are the fuzzy sets, $f_{i}$ is the outputs within the fuzzy region specified by the fuzzy rule, and $p_{i}, q_{i}$, and $r_{i}$ are the design parameters that are determined during the training process. Figure 3 shows the corresponding equivalent ANFIS architecture. The five layers comprising the ANFIS structure are briefly described as follows:

Layer 1: every node $i$ in this layer is an adaptive node, whose output is defined as follows:

$$
\begin{aligned}
& o_{i}^{1}=\mu A_{i}(x), \text { for } i=1,2 \text { or, } \\
& o_{i}^{1}=\mu B_{i-2}(y), \text { for } i=3,4,
\end{aligned}
$$

where $x$ or $y$ is the input to the ith node and $A_{i}$ or $B_{i-2}$ is a fuzzy label.

Layer 2: in the second layer, the nodes are fixed nodes, labeled $M$, indicating that they perform as a simple multiplier. For example,

$$
o_{i}^{2}=w_{i}=\mu_{A i}(x) \mu_{B i}(y), i=1,2 .
$$

Layer 3: every node in this layer is a fixed node labeled $N$. The ith node calculates the ratio of the rule's firing strength to the sum of all rules' firing strengths:

$$
o_{i}^{3}=\bar{w}_{i}=\frac{w_{i}}{w_{1}+w_{2}}, i=1,2
$$




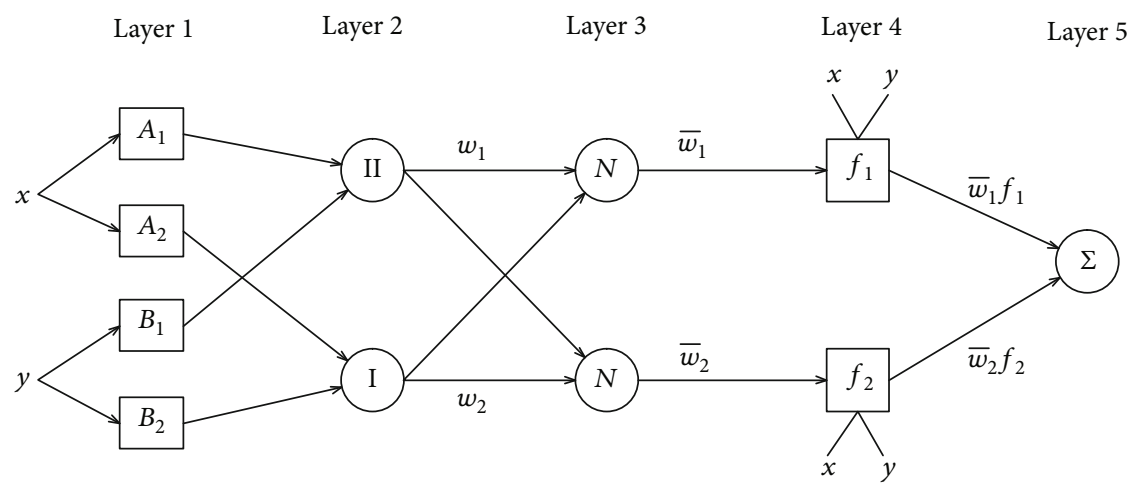

Figure 3: The structure of the ANFIS.

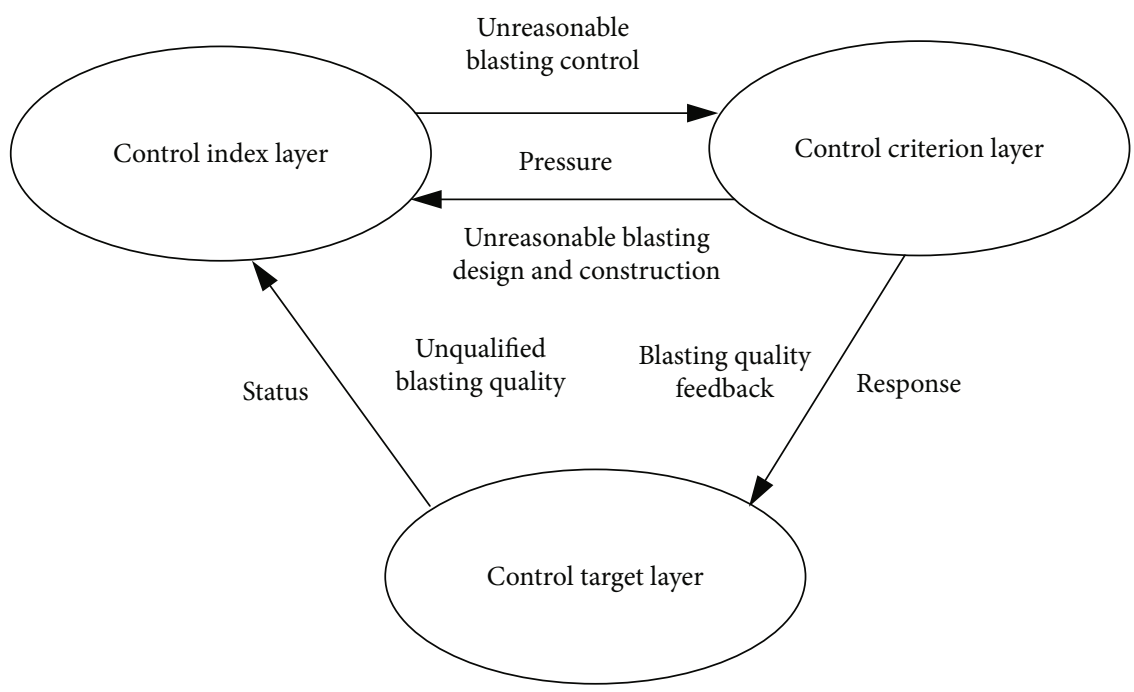

FIGURE 4: PSR concept model of a quality control index system.

Layer 4: every node $i$ in this layer is an adaptive node with a node function as

$$
o_{i}^{4}=\bar{w}_{i} f_{i}=\bar{w}_{i}\left(p_{i} x+q_{i} y+r_{i}\right), i=1,2,
$$

where $\bar{w}_{i}$ is a normalized firing strength from layer 3 and $\left(p_{i}, q_{i}, r_{i}\right)$ is the parameter set of this node.

Layer 5: as the last layer, layer 5 includes a stable and single node, labeled $\sum$, which sums all the signals to calculate the total output:

$$
o_{i}^{5}=\sum \bar{w}_{i} f_{i}=\frac{\sum_{i} w_{i} f_{i}}{\sum_{i} w_{i}}
$$

\subsection{Methodological Framework}

2.2.1. Construction Principle and Frame Structure Design. The selection of tunnel smooth blasting quality control index should follow the principles of comprehensiveness and representativeness, innovation and science, systematicness and hierarchy, maneuverability, dynamics, and scientific quantification. On the basis of these control principles and taking the Pressure-State-Response (PSR) concept model [27-29] proposed by the United Nations Economic Cooperation and Development Agency as a reference, this paper establishes the PSR concept model of a quality control index system of tunnel smooth blasting construction (see Figure 4) based on the actual situation of the tunnel smooth blasting construction process. The PSR model separates the indicators into three groups of categories: (1) the "pressure" indicator has an impact factor that reflects the human activities and leads to unreasonable blasting quality of the rock tunnel; (2) the "state" indicator, which illustrates the quality state and control process of smooth blasting; and (3) the "response" indicator, which measures its smooth blasting quality evaluation service. Thus, it can clearly reflect the relationship between the relevant factors of tunnel smooth blasting quality, thereby enabling decision-makers to address the primary and secondary relations in the complex smooth blasting quality control index and then compare and judge one by one, optimize the best control index, feed the control results back to the control system, reverse the performance of the optimal tunnel smooth blasting quality control index, and obtain the optimal index quality control range to ensure the integrity and effectiveness of the final control index system.

2.2.2. Construction Method. The main process of establishing the quality control index system for tunnel smooth blasting is 


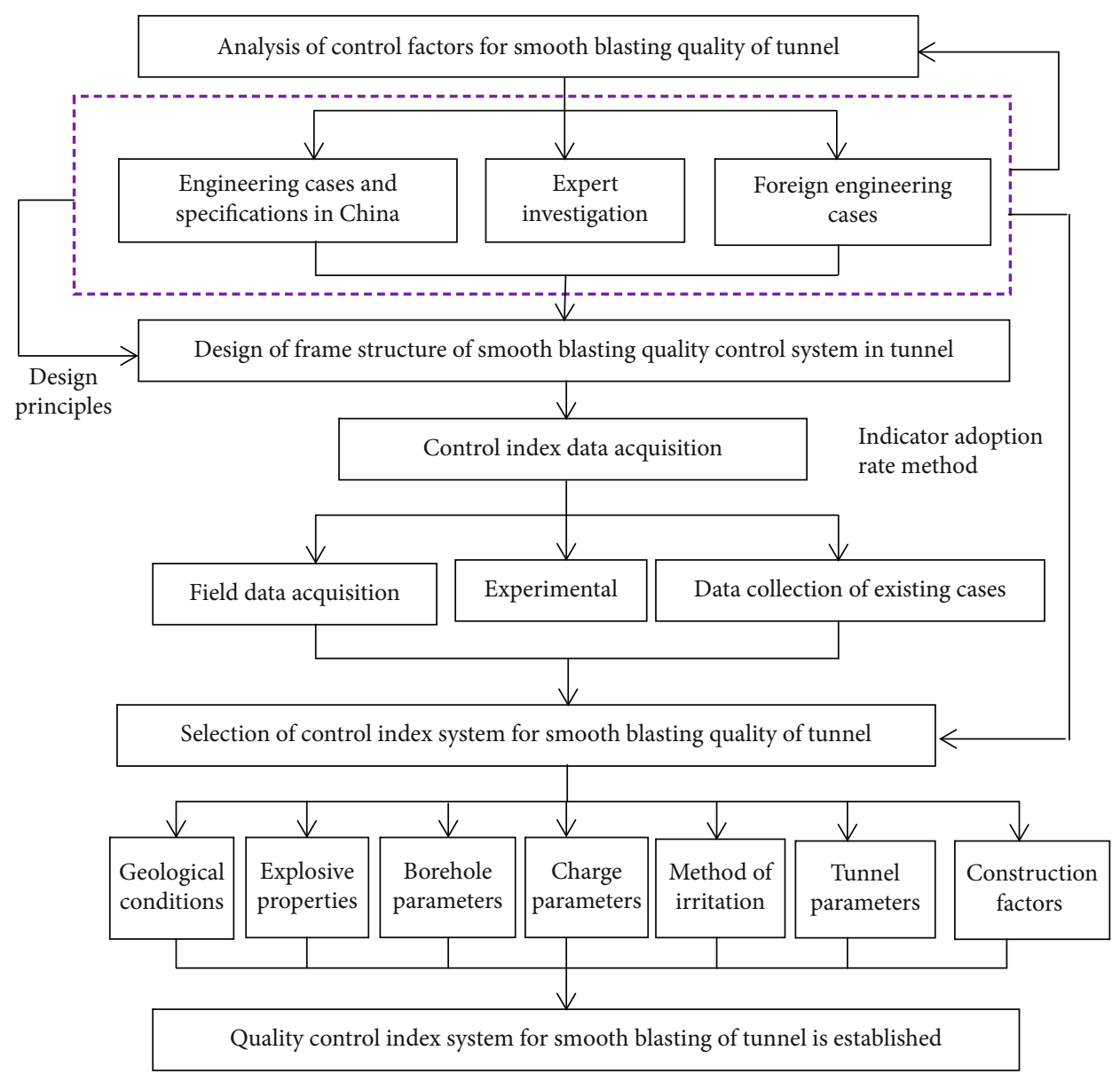

Figure 5: Construction process of quality control index system for tunnel smooth blasting.

shown in Figure 5. The primary theoretical methods used in the construction of the control index system are gray correlation [30] and principal component analyses [31].

To perform the gray correlation analysis, the reference sequence can be defined as $x_{0}=\left[x_{0}(1), x_{0}(2), \cdots, x_{0}(m)\right]$ while the comparative sequence can be $x_{\mathrm{i}}=\left[x_{\mathrm{i}}(1), x_{\mathrm{i}}(2), \cdots\right.$, $\left.x_{\mathrm{i}}(m)\right]$, and $i=1,2, \cdots, n$. The reference sequence denoted as $x_{0}^{\prime}$ can be expressed as Eq. (15) while the comparative sequence indicated as $x_{i}^{\prime}$ can be described as Eq. (16).

$$
\begin{aligned}
x_{0}^{\prime} & =\left[x_{0}^{\prime}(1), x_{0}^{\prime}(2), \cdots, x_{0}^{\prime}(m)\right] \\
& =\left[\frac{x_{0}(1)}{\left(\sum_{j=1}^{m} x_{0}(j)\right) / m}, \frac{x_{0}(2)}{\left(\sum_{j=1}^{m} x_{0}(j)\right) / m}, \cdots, \frac{x_{0}(m)}{\left(\sum_{j=1}^{n} x_{0}(j)\right) / m}\right],
\end{aligned}
$$

$$
\begin{aligned}
x_{i}^{\prime} & =\left[x_{i}^{\prime}(1), x_{i}^{\prime}(2), \cdots, x_{i}^{\prime}(m)\right] \\
& =\left[\frac{x_{i}(1)}{\left(\sum_{j=1}^{m} x_{i}(j)\right) / m}, \frac{x_{i}(2)}{\left(\sum_{j=1}^{m} x_{i}(j)\right) / m}, \cdots, \frac{x_{i}(\mathrm{~m})}{\left(\sum_{j=1}^{m} x_{i}(j)\right) / m}\right] .
\end{aligned}
$$

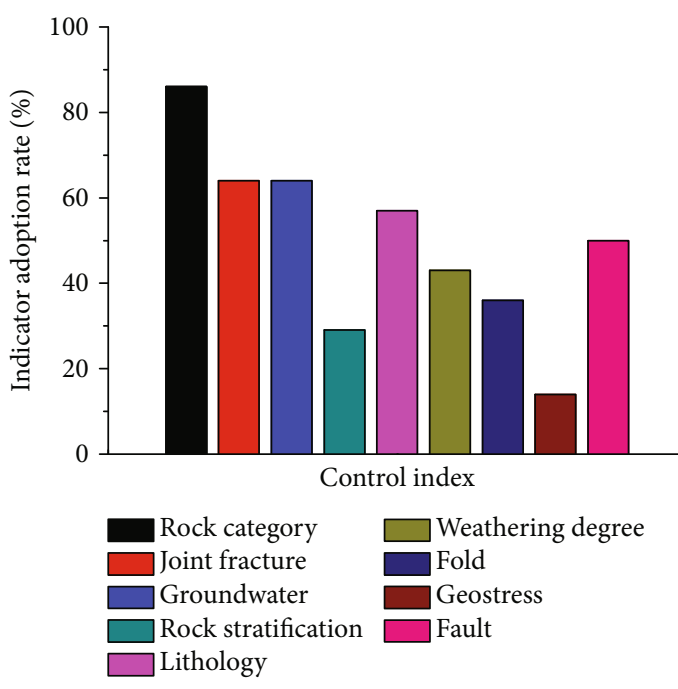

FIgURE 6: Geological conditions.

The correlation coefficient is defined as:

$$
\eta_{0 i}(j)=\frac{\Delta_{\min }+w \Delta_{\max }}{\left|x_{\mathrm{o}}(j)-x_{i}(j)+w \Delta_{\max }\right|},
$$




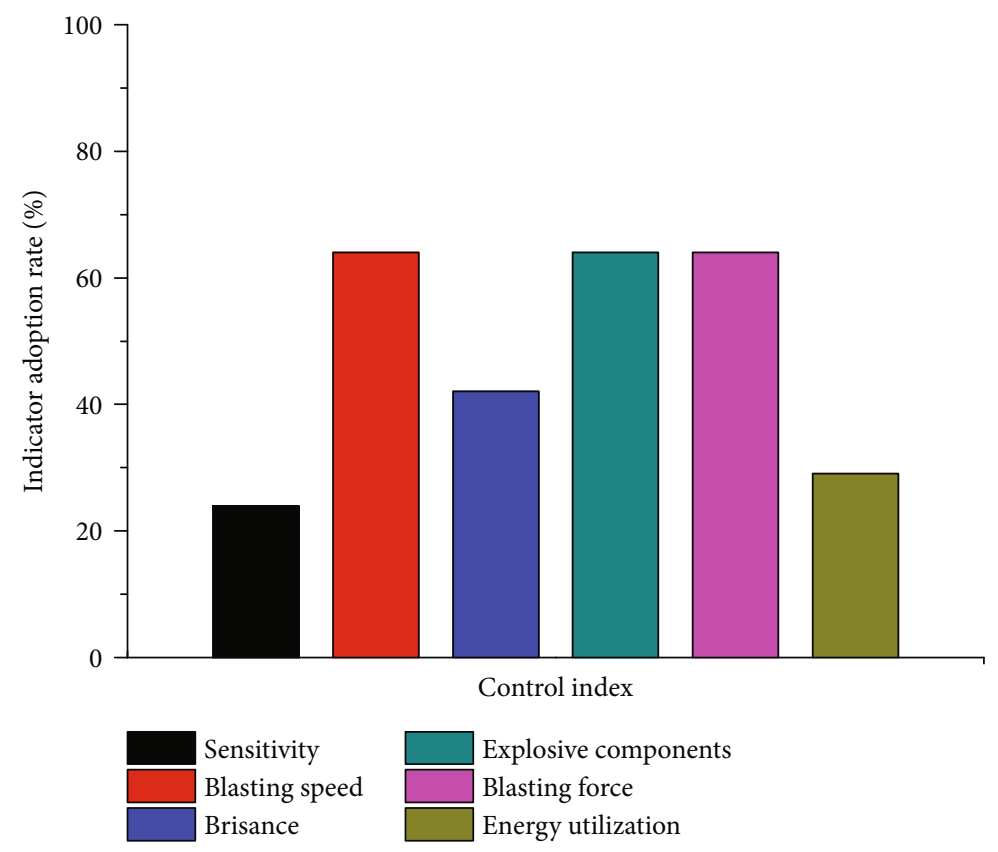

FIgURE 7: Explosive properties.

in which $w$ is the resolution coefficient, $\Delta_{\min }$ is the minimum difference between the two sequences, and $\Delta_{\max }$ is the maximum difference between the two sequences.

The principal component analyses model is:

$$
X=T E^{T}+F,
$$

in which $X$ is the input matrix $(\mathrm{m} \times \mathrm{e})$ which represents original parameters, $T$ is the score matrix $(\mathrm{m} \times k)$ which represents the relationship between original parameters, $E$ is the loading matrix $(e \times j)$ which represents the contribution of original parameters, and $F$ is the residual matrix $(\mathrm{m} \times \mathrm{e})$ which represents the uncaptured variance. $m$ is the number of time steps, $e$ is the number of original parameters, and $j$ is the number of principal components.

2.3. Control Index Data Collection. Field investigation, expert consultation, experimental research, existing engineering case data collection, and other methods were used to collect the control index data.

2.3.1. On-Site Investigation and Expert Consultation. In accordance with the influencing factors of tunnel smooth blasting quality control, field investigation and expert consultation method are conducted with seven aspects of geological conditions, explosive properties, borehole parameters, charge parameters, method of initiation, tunnel parameters, and construction factors and a total of 43 influencing factors to evaluate the importance level of qualitative and quantitative indexes, which are divided into five levels: 1 represents very important ( 5 points), 2 represents more important ( 4 points), 3 represents generally important (3 points), 4 represents less important ( 2 points), and 5 represents very unimportant (1 point). The statistical results of field investigation and expert consultation show that the adoption rate of the indicators below level-1 subsection-5 is less than $60 \%$. In accordance with the maneuverability, science, and effectiveness of tunnel smooth blasting quality control, this paper lists only the (very important) adoption rate that impacts the tunnel smooth blasting quality at level-1 subsection- 5 because of space limitations; see Figures 6-12.

Figure 6 shows that the index adoption rate of rock category is $86 \%$, the index adoption rate of joint fracture is $64 \%$, the index adoption rate of groundwater is $64 \%$, and the adoption rate of other indexes is less than $60 \%$.

Figure 7 shows that the index adoption rate of explosive components is $64 \%$, the index adoption rate of blasting force is $64 \%$, the index adoption rate of blasting speed is $64 \%$, and the adoption rate of other indexes is less than $60 \%$.

Figure 8 shows that the index adoption rate of borehole depth is $71 \%$, the index adoption rate of neighboring eyes spacing is $64 \%$, the index adoption rate of minimum resistance line is $79 \%$, the index adoption rate of neighboring eyes dense factor is $64 \%$, and the adoption rate of other indexes is less than $60 \%$.

Figure 9 shows that the index adoption rate of linear charge density is $64 \%$, the index adoption rate of noncoupling coefficient is $60 \%$, the index adoption rate of plugging quality is $71 \%$, and the adoption rate of other indexes is less than $60 \%$.

Figure 10 shows that the index adoption rate of sequence of initiation is $93 \%$, the index adoption rate of time difference of initiation is $64 \%$, the index adoption rate of method of initiation is $71 \%$, and the adoption rate of other indexes is less than $60 \%$.

Figure 11 shows that the index adoption rate of the excavation method is $71 \%$, the index adoption rate of blasting method is $64 \%$, the index adoption rate of excavation section is $64 \%$, and the adoption rate of other indexes is less than $60 \%$. 


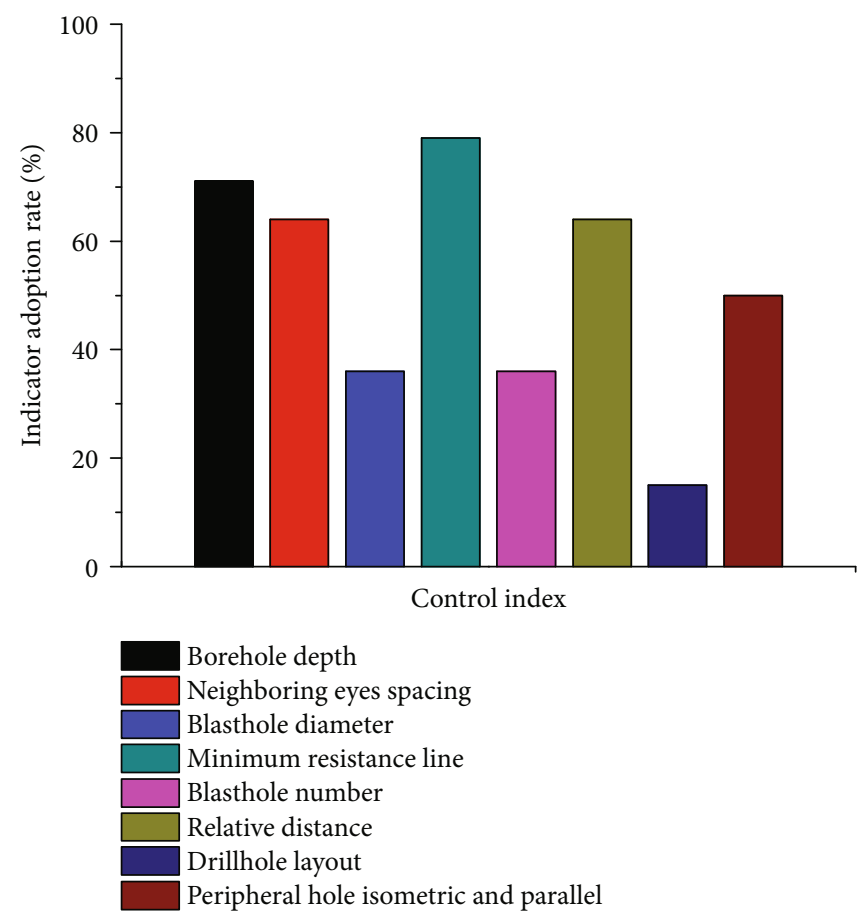

FigURE 8: Borehole parameters.

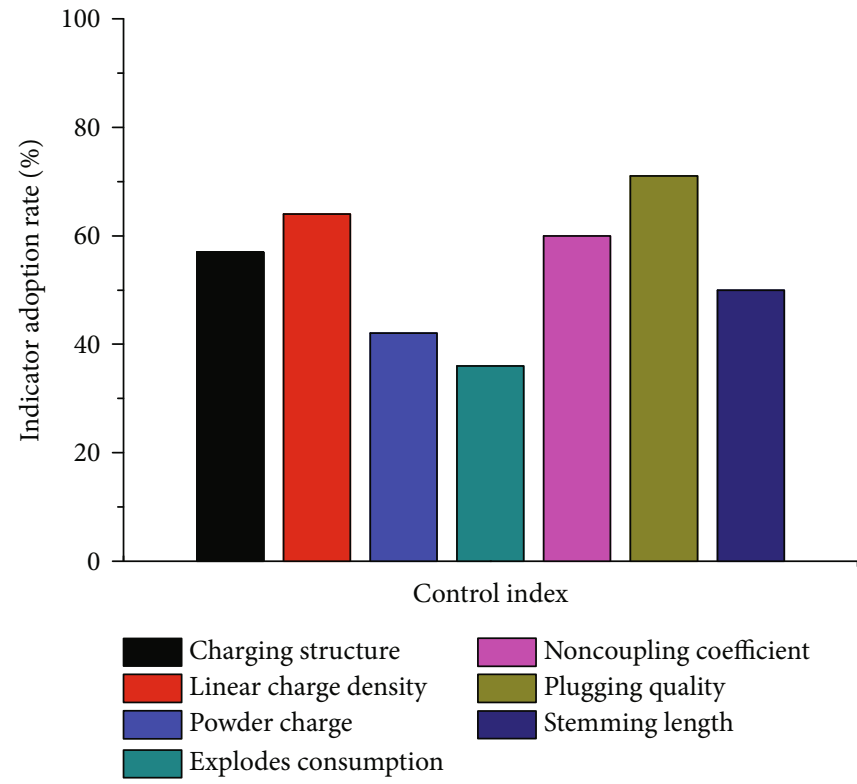

FIGURE 9: Charge parameters.

Figure 12 shows that the index adoption rate of drilling accuracy is $67 \%$, the index adoption rate of measuring and setting out (including midline or elevation deviation) is $64 \%$, the index adoption rate of on-site management system is $71 \%$, and the adoption rate of other indexes is less than $60 \%$.

2.3.2. Experimental Research. The experimental study is mainly based on the Chengdu-Chongqing high-speed rail
Da'an Tunnel [32]. Total length of the tunnel is about $5050 \mathrm{~m}$, while the excavated radius and height are $7.45 \mathrm{~m}$ and $11.08 \mathrm{~m}$, respectively. The lithology exposed on both sides of the syncline includes mudstone and sandstone with age of Jurassic (J). Overlying formations consist of soft silty clay with ages of Holocene series in Quaternary system $\left(Q_{4}^{d 1+p 1}\right)$, soft-flowing plastic silty clay, silty clay, slope residual $\left(Q_{4}^{d 1+e 1}\right)$ silty clay, and colluvial deposits $\left(Q_{4}^{d 1+c o 1}\right)$. Moreover, the underlying formations are Shaxi group of middle 


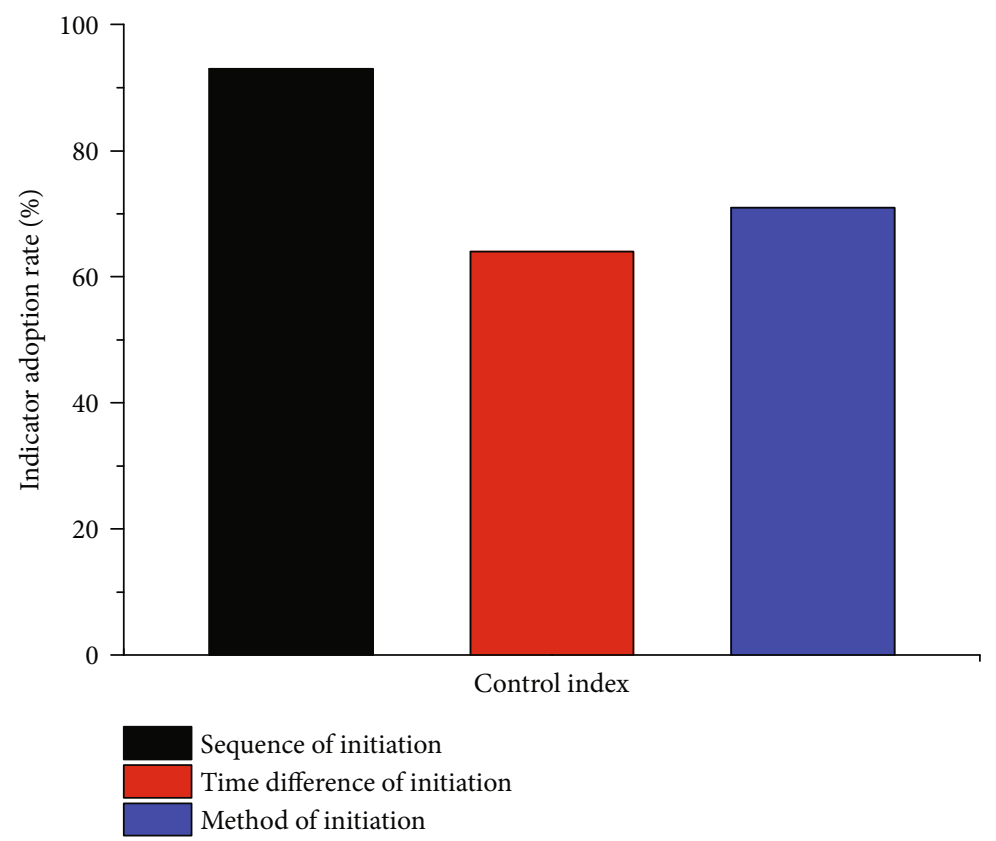

Figure 10: Method of initiation.

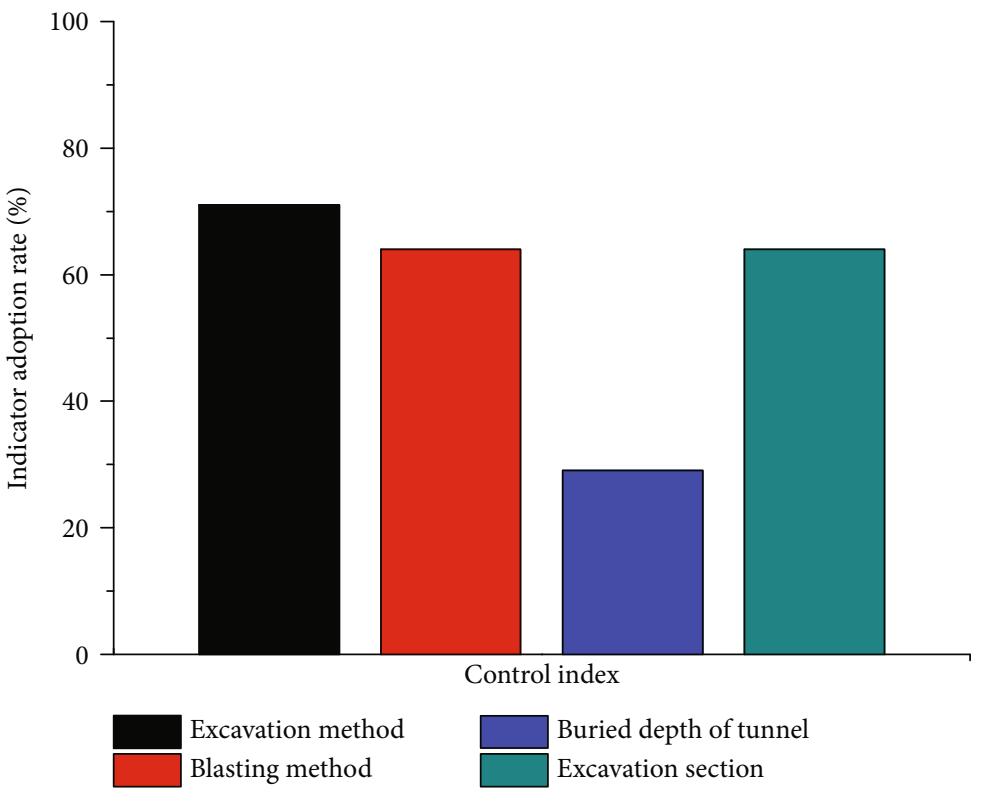

Figure 11: Tunnel parameters.

Jurassic (J), including sandstone, mudstone, sandstone, and argillaceous sandstone. Field and numerical tests were conducted to collect quantitative data, and the main indicators collected in the field test include eight indicators: rock category, neighboring eyes spacing, borehole depth, number of boreholes, charge quantity, minimum resistance line, maximum infrared temperature, and minimum infrared temperature. Field data acquisition test is shown in Figure 13. The numerical test collected seven main indexes [32]: neighboring eyes spacing, minimum resistance line, relative distance, linear charge density, rock category, blasting speed, and measuring and setting out.

2.3.3. Collection of Existing Engineering Case Data. The existing engineering case data collection is mainly aimed at collecting the control indexes used in blasting construction of all kinds of tunnels and underground engineering reported in the existing literature to obtain the most sample data and provide more information for tunnel smooth blasting quality control. Seventy-seven tunnel and underground engineering 


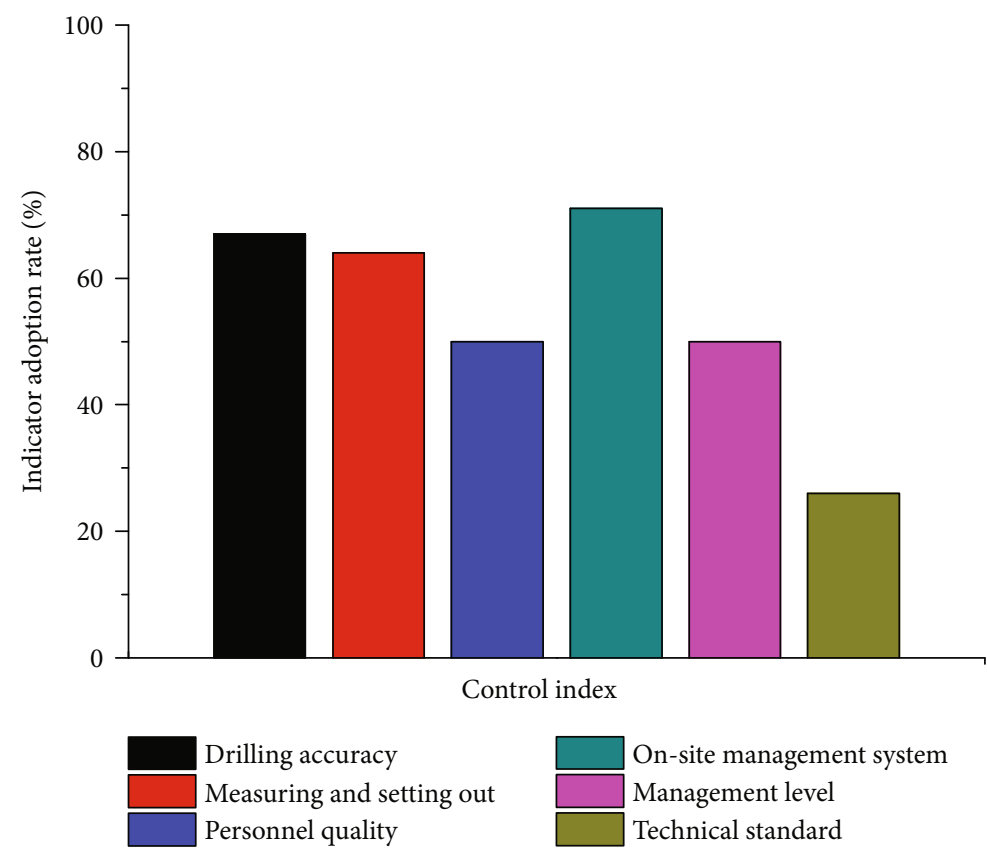

Figure 12: Construction factors.

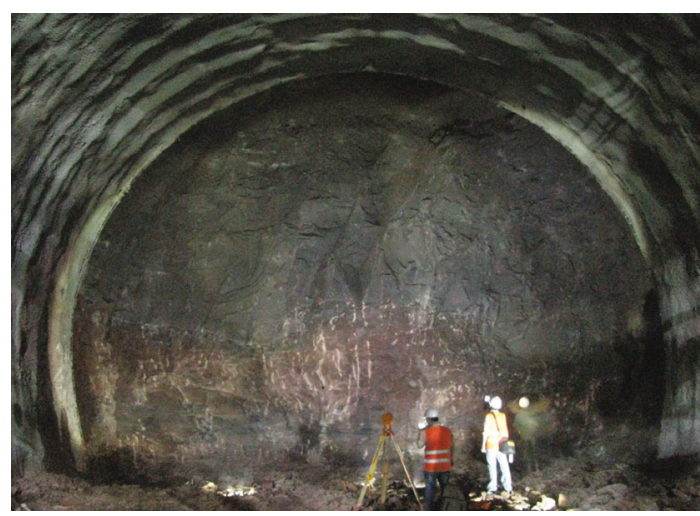

FIgURE 13: Field data acquisition tests.

cases were collected, and the collected control indexes mainly include 23 indexes, such as rock category, borehole depth, and neighboring eyes spacing, as shown in Table 1.

\subsection{Establishment of Quality Control Index System}

2.4.1. Primary Election of Quality Control Index System. On the basis of the factors that influence the quality of tunnel smooth blasting, this paper analyzes the index adoption rate of the control indexes involved in a domestic tunnel and underground project from three aspects, namely, domestic project case statistics, standard statistics, and foreign project case statistics. A total of 210 cases and 43 indicators were counted in domestic project cases, as shown in Figures 14-20.

To ensure the validity, feasibility, and scientificity of the control index while analyzing the above figures, only the index with the indicator adoption rate $\geq 60 \%$ is analyzed. Therefore, for geological conditions, the index adoption rate of rock category is $89 \%$; for the borehole blasting design, the index adoption rate of neighboring eyes spacing is $92.4 \%$, the index adoption rate of minimum resistance line is $86.2 \%$, the index adoption rate of relative distance is $66.2 \%$, and the adoption rate of linear charge density is $77.1 \%$. The adoption rates of construction factors, drilling accuracy, measuring and setting out, personnel quality, on-site management system, and other indicators are low.

The statistics on the adoption rate of control indicators in various current regulations in China mainly include nine specifications, such as Technical Specifications for Construction of Highway Tunnel (JTG/T 3660-2020), Code for construction and acceptance of metro engineering (2012 version) (GB 50299-1999), and Code for construction on tunnel of railway (TB 10204-2002), as shown in Figure 21. The figure shows that, in the current specification, the index adoption rate of charge noncoupling coefficient is $44 \%$, the index adoption rate of neighboring eyes spacing is $100 \%$, the index adoption rate of minimum resistance line is $100 \%$, the index adoption rate of relative distance is $67 \%$, the adoption rate of linear charge density is $100 \%$, the adoption rate of rock category is $100 \%$, and the adoption rate of borehole depth is $11 \%$.

The quality control index of tunnel smooth blasting used in foreign engineering cases is analyzed statistically $[5,6,33-48]$, as shown in Figure 22. The figure shows that the index adoption rate of charge noncoupling coefficient is $10 \%$, the index adoption rate of neighboring eyes spacing is $100 \%$, the index adoption rate of neighboring eyes minimum resistance line is $100 \%$, the index adoption rate of relative distance is $30 \%$, the adoption rate of linear charge density is $100 \%$, the adoption rate of borehole depth is $40 \%$, the 
TABLe 1: Collection of existing engineering case data.

\begin{tabular}{lccccc}
\hline No. & Index & No. & Index & No. & Index \\
\hline 1 & Rock category & 9 & Minimum resistance line & 17 & Excavation method \\
2 & Joint fracture & 10 & Relative distance & 18 & Blasting method \\
3 & Groundwater & 11 & Linear charge density & 19 & Buried depth of tunnel \\
4 & Explosive components & 12 & Noncoupling coefficient & 20 & Excavation section \\
5 & Blasting force & 13 & Plugging quality & 21 & Drilling accuracy \\
6 & Blasting speed & 14 & Sequence of initiation & 22 & Measuring and setting out \\
7 & Borehole depth & 15 & Time difference of initiation & 23 & On-site management system \\
8 & Neighboring eyes spacing & 16 & Method of initiation & & \\
\hline
\end{tabular}

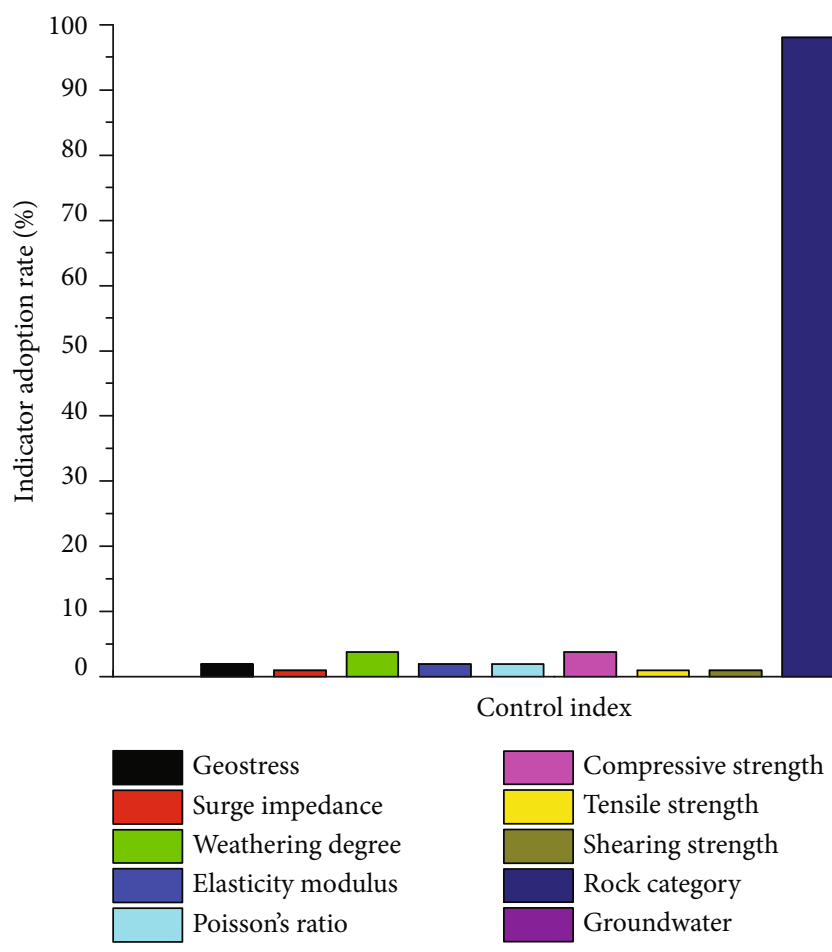

FIGURE 14: Geological conditions.

adoption rate of rock category is $100 \%$, and the adoption rate of measuring and setting out is $30 \%$.

Therefore, combined with the domestic engineering case statistics, standard statistics, foreign engineering case statistics, and tunnel smooth blasting quality control index data collection, from the seven aspects of geological conditions, explosive properties, borehole parameters, charge parameters, method of initiation, tunnel parameters, and construction factors, the tunnel smooth blasting quality control index system was primarily established, with a total of 22 indicators, as seen in Table 2 .

2.4.2. Selection of Quality Control Index System. In accordance with the principle of constructing the quality control index system of tunnel smooth blasting, the control index needs to be screened and modified, and the modified method mainly adopts gray correlation [30] and principal component analyses [31].
(1) Geological conditions. X1-X3 represent the rock category, joint fracture, and groundwater, respectively. The correlation degree of geological condition index calculated by gray correlation analysis is shown in Table 3

The above analysis indicates that in each control index, the rock category has the highest correlation degree, followed by the joint fracture and the groundwater.

The normalized eigenvectors of geological condition indexes calculated by principal component analysis are shown in Table 4 , and the eigenvalues are shown in Table 5.

Combined with the above analysis, findings indicate that the amount of information contained in the first two main components is $96.48 \%$ of the total amount of information, and the first principal component represents X1.

Combined with the above gray correlation and principal component analyses, findings indicate that the optimal characteristic index of geological conditions is the rock category. 


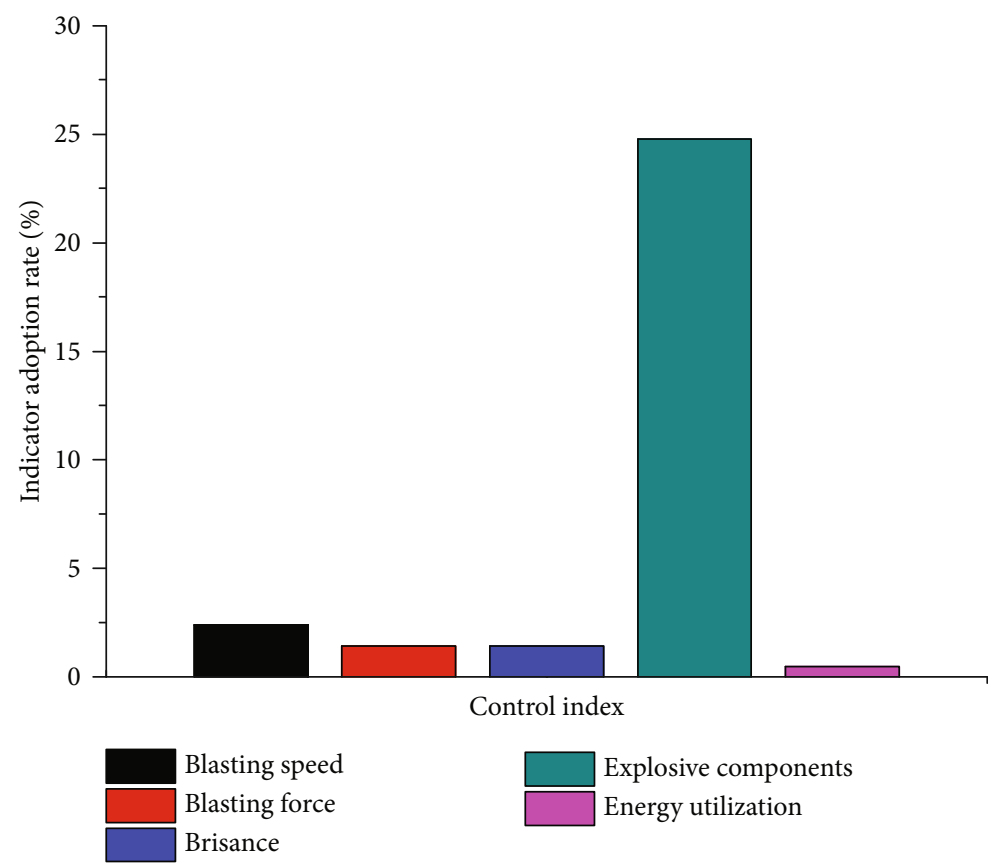

Figure 15: Explosive properties.

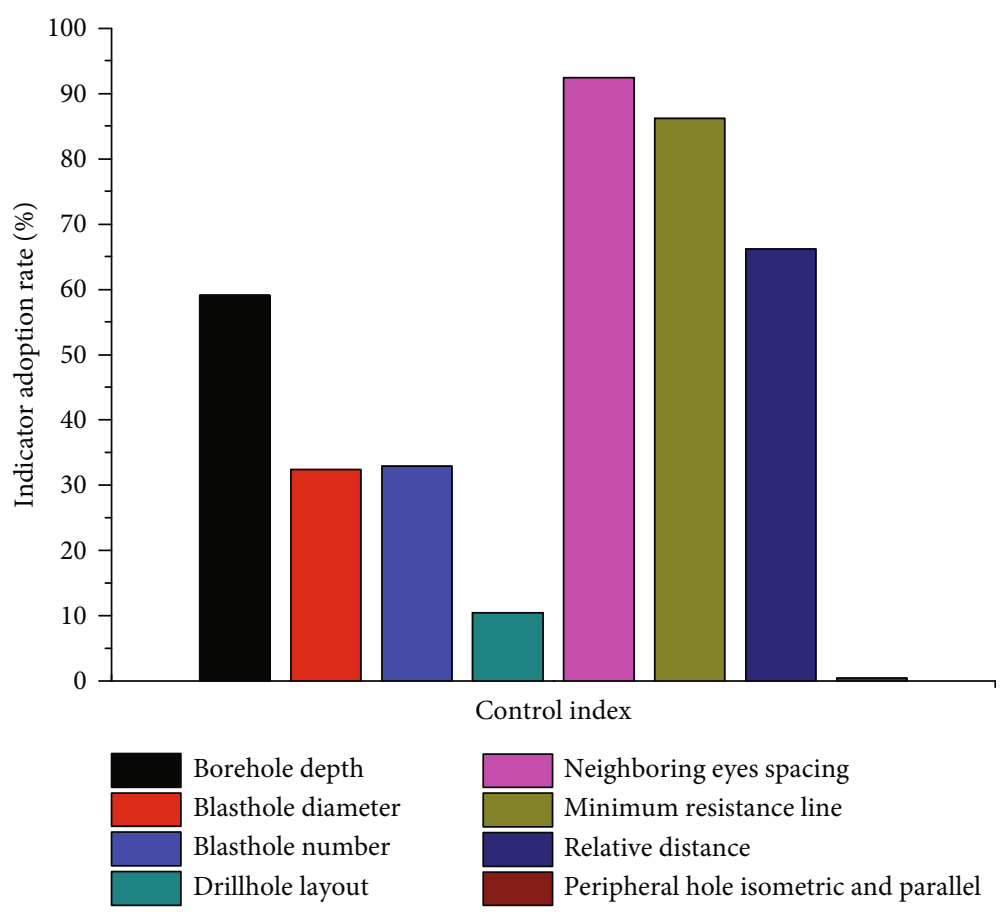

FiguRE 16: Borehole parameters.

(2) Explosive properties. X1-X3 represent the explosive components, blasting force, and blasting speed, respectively. The correlation degree of the explosive property index calculated by gray correlation analysis is shown in Table 6

The above analysis shows that the most significant influencing factors of correlation degree are blasting force and blasting speed.
The normalized eigenvectors of explosive property indexes calculated by principal component analysis are shown in Table 7 , and the eigenvalues are shown in Table 8.

The above analysis shows that the amount of information contained in the first main component is $77.29 \%$ of the total amount of information, and the first principal component represents X3. Combined with the gray correlation and principal component analyses, findings indicate that the optimal 


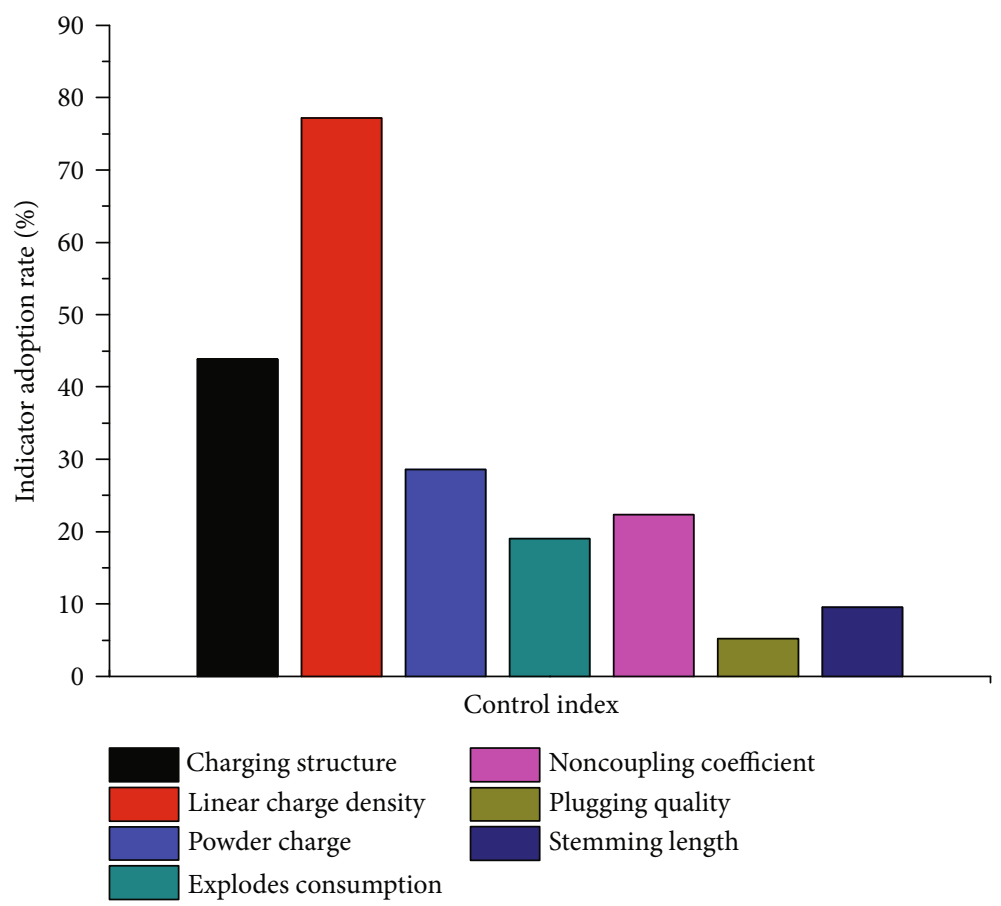

FIGURE 17: Charge parameters.

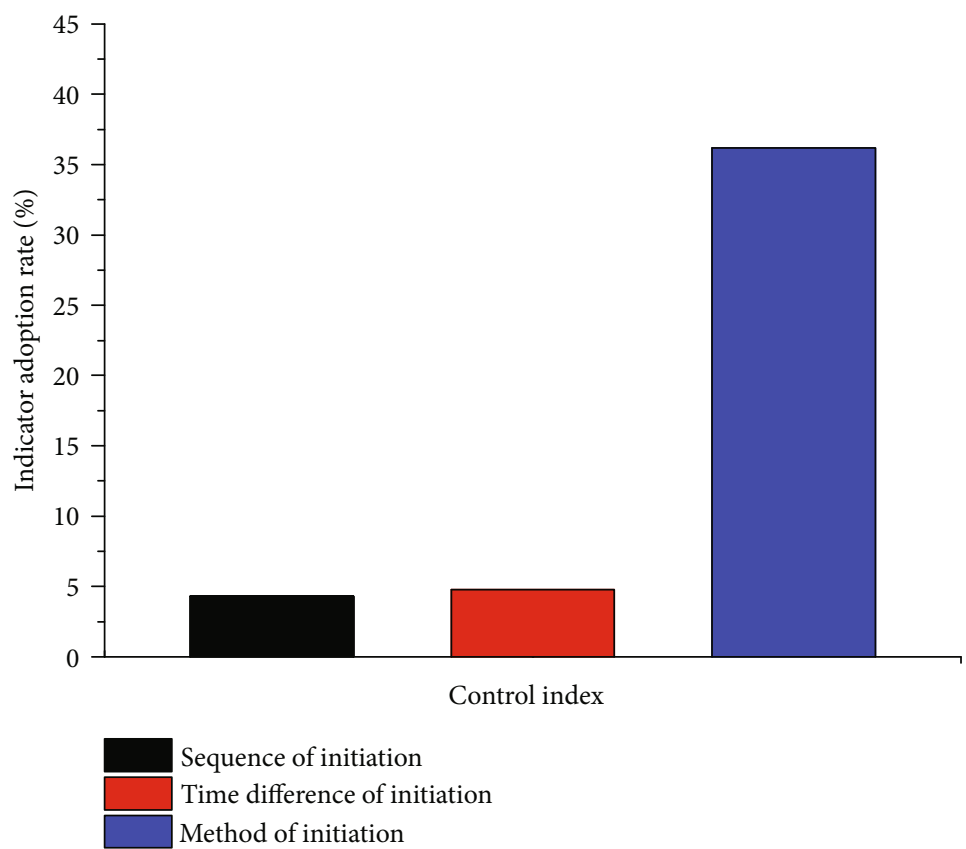

FIGURE 18: Method of initiation.

characteristic index of explosive properties is the blasting speed.

(3) Borehole parameters. $\mathrm{X} 1-\mathrm{X} 4$ represent the borehole depth, neighboring eyes spacing, minimum resistance line, and relative distance, respectively. The correlation degree of the borehole parameter index calculated by gray correlation analysis is shown in Table 9
The above analysis shows that the most significant influencing factor of correlation degree is the minimum resistance line.

The normalized eigenvectors of borehole parameter indexes calculated by principal component analysis are shown in Table 10, and the eigenvalues are shown in Table 11.

Combined with the above analyses, findings indicate that the amount of information contained in the first two main 


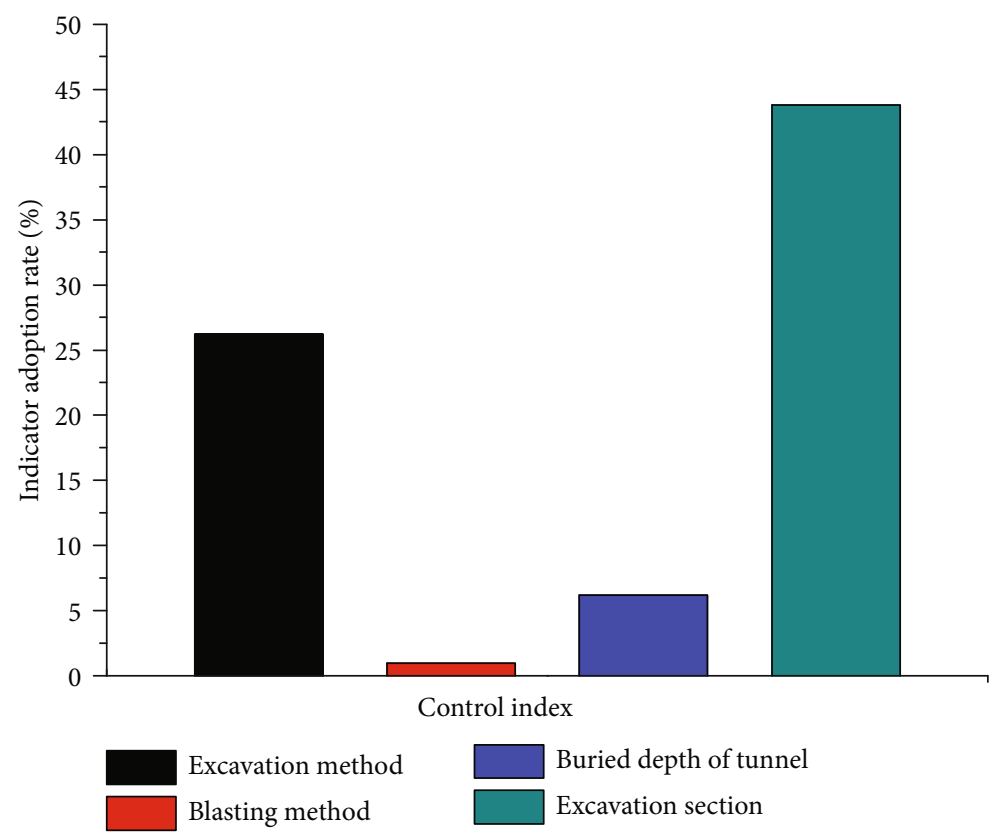

Figure 19: Tunnel parameters.

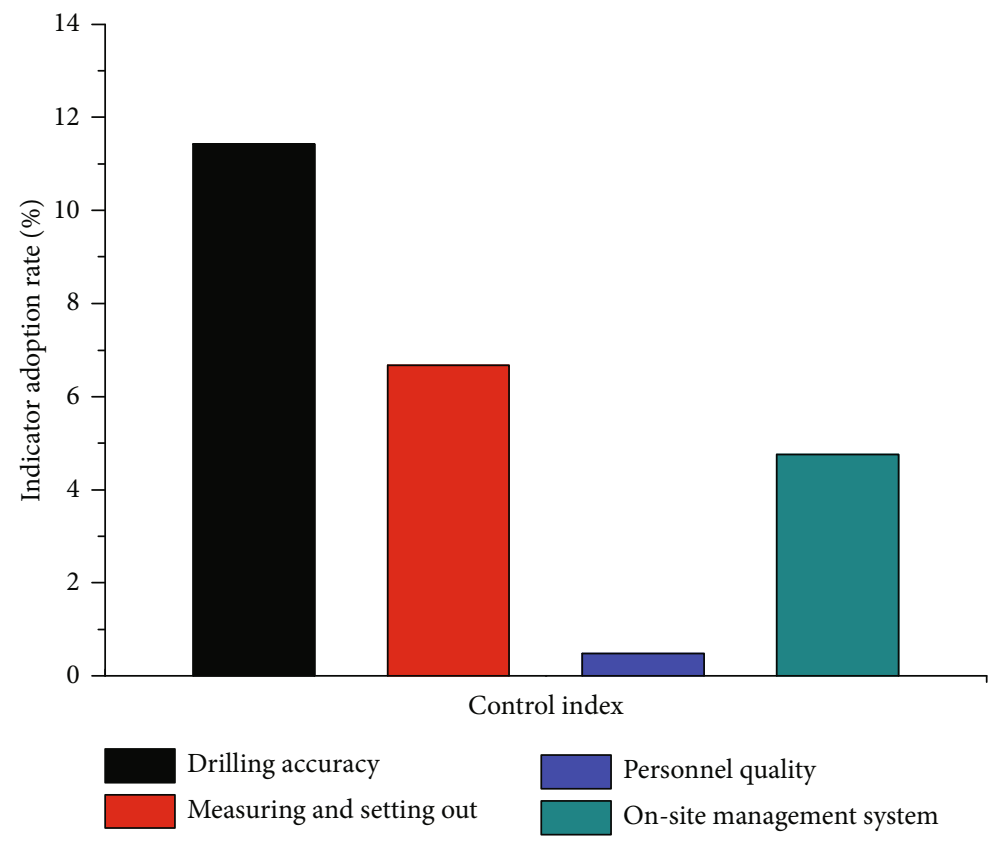

FIGURE 20: Construction factors.

components is $82.37 \%$ of the total amount of information, the first principal component represents $\mathrm{X} 2$, and the second principal component represents X4.

Combined with the above gray correlation and principal component analyses, findings indicate that the optimal characteristic indicators of borehole parameters are the rock category, minimum resistance line, and relative distance.

(4) Charge parameters. $\mathrm{X} 1-\mathrm{X} 3$ represent the linear charge density, noncoupling coefficient, and plugging quality, respectively. The correlation degree of charge parameter index calculated by gray correlation analysis is shown in Table 12

The above analysis shows that the first influencing factor of correlation degree is linear charge density, the second influencing factor is plugging quality, and the third is noncoupling coefficient.

The normalized eigenvectors of charge parameter indexes calculated by principal component analysis are shown in Table 13, and the eigenvalues are shown in Table 14. 


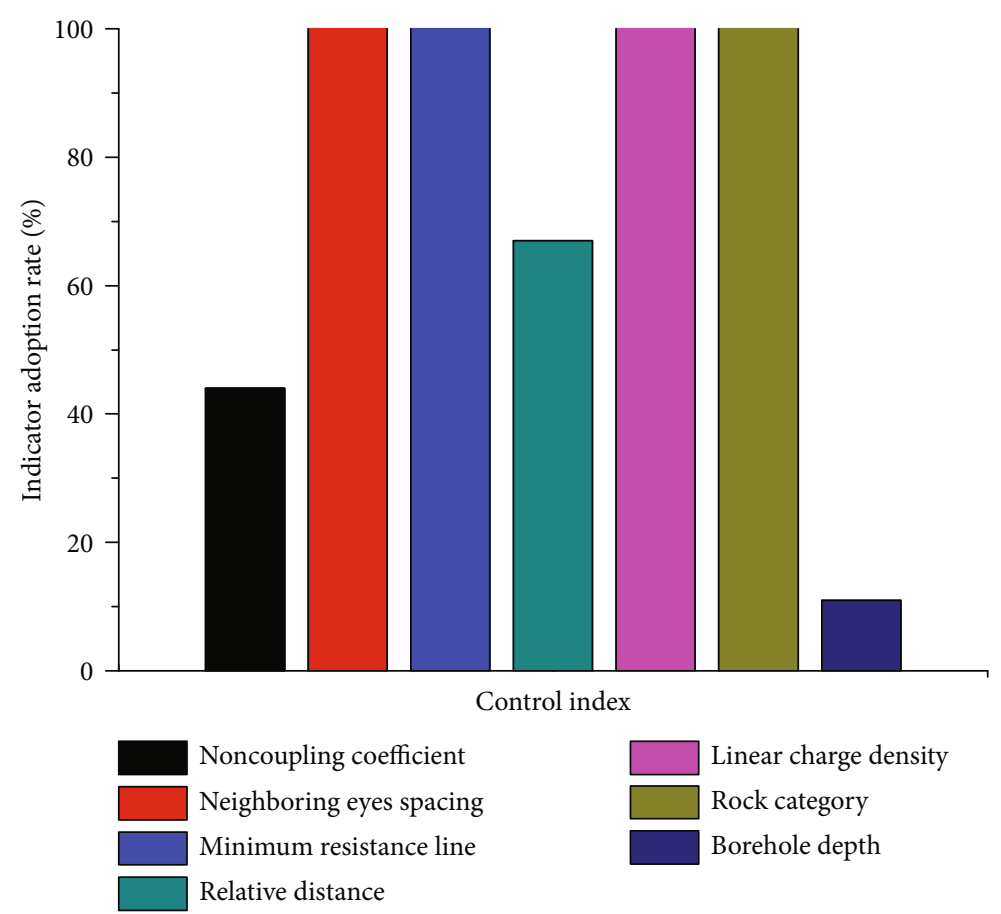

FIGURE 21: Statistics on the adoption rate of quality control index of tunnel blasting in current specification.

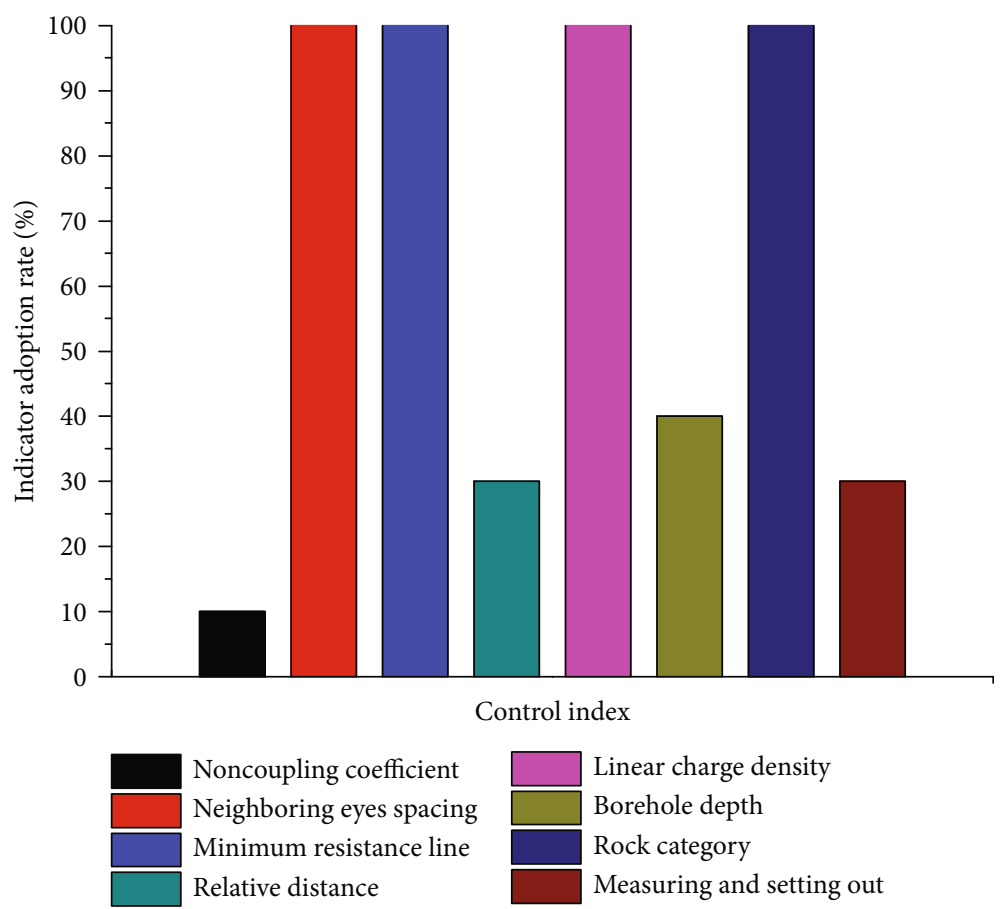

Figure 22: Foreign engineering case statistics.

Combined with the above analysis, findings indicate that the amount of information contained in the first two main components is $76.69 \%$ of the total amount of information, the first principal component represents X3, and the second principal component represents X1.

Combined with the above gray correlation and principal component analyses, findings indicate that the optimal characteristic index of charge parameters is the linear charge density.
(5) Method of initiation. X1-X3 represent the sequence of initiation, time difference of initiation, and method of initiation, respectively. The correlation degree of the method of initiation index calculated by gray correlation analysis is shown in Table 15.

The above analysis shows that the first influencing factor of correlation degree is the sequence of initiation, the second 
TABLe 2: Primary election of quality control index system for tunnel smooth blasting.

\begin{tabular}{|c|c|c|}
\hline Control target layer & Control criterion layer & Control index layer \\
\hline \multirow{21}{*}{ Quality control index system for tunnel smooth blasting } & \multirow{3}{*}{ Geological conditions } & Rock category \\
\hline & & Joint fracture \\
\hline & & Groundwater \\
\hline & \multirow{3}{*}{ Explosive properties } & Explosive components \\
\hline & & Blasting force \\
\hline & & Blasting speed \\
\hline & \multirow{4}{*}{ Borehole parameters } & Borehole depth \\
\hline & & Neighboring eyes spacing \\
\hline & & Minimum resistance line \\
\hline & & Relative distance \\
\hline & \multirow{3}{*}{ Charge parameters } & Linear charge density \\
\hline & & Noncoupling coefficient \\
\hline & & Plugging quality \\
\hline & \multirow{3}{*}{ Method of initiation } & Sequence of initiation \\
\hline & & Time difference of initiation \\
\hline & & Method of initiation \\
\hline & \multirow{3}{*}{ Tunnel parameters } & Excavation method \\
\hline & & Blasting method \\
\hline & & Excavation section \\
\hline & \multirow[b]{2}{*}{ Construction factors } & Drilling accuracy \\
\hline & & Measuring and setting out \\
\hline
\end{tabular}

TABLE 3: Correlation degree of geological condition index.

\begin{tabular}{lc}
\hline Control index & Correlation degree \\
\hline Rock category & 0.6493 \\
Joint fracture & 0.6423 \\
Groundwater & 0.5008 \\
\hline
\end{tabular}

TABLE 4: Normalized eigenvectors of geological condition index.

\begin{tabular}{lccc}
\hline Control index & Control index 1 & Control index 2 & Control index 3 \\
\hline X1 & 0.6462 & 0.2577 & 0.7183 \\
X2 & 0.6335 & 0.3438 & -0.6932 \\
X3 & -0.4256 & 0.903 & 0.0589 \\
\hline
\end{tabular}

TABLE 5: Eigenvalues of geological condition index.

\begin{tabular}{lccc}
\hline No. & Eigenvalue & Percentage (\%) & Cumulative percentage (\%) \\
\hline 1 & 2.145 & 71.50 & 71.50 \\
2 & 0.7495 & 24.98 & 96.48 \\
3 & 0.1055 & 3.51 & 100 \\
\hline
\end{tabular}

is the time difference of initiation, and the third is the method of initiation.

The normalized eigenvectors of the method of initiation index calculated by principal component analysis are shown in Table 16, and the eigenvalues are shown in Table 17.
TABLE 6: Correlation degree of the explosive property index.

\begin{tabular}{lc}
\hline Control index & Correlation degree \\
\hline Explosive components & 0.487 \\
Blasting force & 0.544 \\
Blasting speed & 0.544 \\
\hline
\end{tabular}

TABLE 7: Normalized eigenvectors of explosive property index.

\begin{tabular}{lccc}
\hline Control index & Control index 1 & Control index 2 & Control index 3 \\
\hline X1 & -0.5752 & 0.5905 & 0.5661 \\
X2 & 0.5342 & 0.7952 & -0.2868 \\
X3 & 0.6195 & -0.1374 & 0.7729 \\
\hline
\end{tabular}

TABLE 8: Eigenvalues of explosive property index.

\begin{tabular}{lccc}
\hline No. & Eigenvalue & Percentage (\%) & Cumulative percentage (\%) \\
\hline 1 & 2.3189 & 77.29 & 77.29 \\
2 & 0.513 & 17.10 & 94.39 \\
3 & 0.168 & 5.60 & 100 \\
\hline
\end{tabular}

Combined with the above analysis, findings indicate that the amount of information contained in the first two main components is $78.06 \%$ of the total amount of information, the first principal component represents X1, and the second principal component represents X3. 
TABLE 9: Correlation degree of the borehole parameter index.

\begin{tabular}{lc}
\hline Control index & Correlation degree \\
\hline Borehole depth & 0.5787 \\
Neighboring eyes spacing & 0.6063 \\
Minimum resistance line & 0.6655 \\
Relative distance & 0.6473 \\
\hline
\end{tabular}

TABLE 10: Normalized eigenvectors of borehole parameter index.

\begin{tabular}{lcccc}
\hline $\begin{array}{l}\text { Control } \\
\text { index }\end{array}$ & $\begin{array}{c}\text { Control } \\
\text { index 1 }\end{array}$ & $\begin{array}{c}\text { Control } \\
\text { index 2 }\end{array}$ & $\begin{array}{c}\text { Control } \\
\text { index 3 }\end{array}$ & $\begin{array}{c}\text { Control } \\
\text { index 4 }\end{array}$ \\
\hline $\mathrm{X} 1$ & 0.4328 & -0.2873 & 0.8544 & -0.0101 \\
$\mathrm{X} 2$ & 0.6536 & 0.1733 & -0.2809 & -0.6811 \\
$\mathrm{X} 3$ & 0.5135 & -0.5147 & -0.4269 & 0.5377 \\
$\mathrm{X} 4$ & 0.349 & 0.7889 & 0.0944 & 0.4968 \\
\hline
\end{tabular}

TABLE 11: Eigenvalues of borehole parameter index.

\begin{tabular}{lccc}
\hline No. & Eigenvalue & Percentage (\%) & Cumulative percentage (\%) \\
\hline 1 & 2.1176 & 52.94 & 52.94 \\
2 & 1.1776 & 29.43 & 82.37 \\
3 & 0.6932 & 17.33 & 99.71 \\
4 & 0.0116 & 0.28 & 100 \\
\hline
\end{tabular}

TABLE 12: Correlation degree of the charge parameter index.

\begin{tabular}{lc}
\hline Control index & Correlation degree \\
\hline Linear charge density & 0.6502 \\
Noncoupling coefficient & 0.6109 \\
Plugging quality & 0.6383 \\
\hline
\end{tabular}

TABLE 13: Normalized eigenvectors of charge parameter index.

\begin{tabular}{lccc}
\hline Control index & Control index 1 & Control index 2 & Control index 3 \\
\hline X1 & 0.2076 & 0.9061 & 0.3687 \\
X2 & 0.6577 & -0.4083 & 0.6331 \\
X3 & -0.7241 & -0.1111 & 0.6806 \\
\hline
\end{tabular}

TABLE 14: Eigenvalues of charge parameter index.

\begin{tabular}{lccc}
\hline No. & Eigenvalue & Percentage (\%) & Cumulative percentage (\%) \\
\hline 1 & 1.265 & 42.16 & 42.16 \\
2 & 1.0359 & 34.53 & 76.69 \\
3 & 0.6991 & 23.30 & 100 \\
\hline
\end{tabular}

TABLE 15: Correlation degree of the method of initiation index.

\begin{tabular}{lc}
\hline Control index & Correlation degree \\
\hline Sequence of initiation & 0.7904 \\
Time difference of initiation & 0.7885 \\
Method of initiation & 0.6664 \\
\hline
\end{tabular}

TABLE 16: Normalized eigenvectors of method of initiation index.

\begin{tabular}{lccc}
\hline Control index & Control index 1 & Control index 2 & Control index 3 \\
\hline X1 & 0.6989 & 0.0608 & 0.7126 \\
X2 & 0.6732 & 0.2805 & -0.6842 \\
X3 & -0.2415 & 0.9579 & 0.1551 \\
\hline
\end{tabular}

TABLE 17: Eigenvalues of method of initiation index.

\begin{tabular}{lccc}
\hline No. & Eigenvalue & Percentage (\%) & Cumulative percentage (\%) \\
\hline 1 & 1.3555 & 45.18 & 45.18 \\
2 & 0.9864 & 32.87 & 78.06 \\
3 & 0.6581 & 21.93 & 100 \\
\hline
\end{tabular}

TABLE 18: Correlation degree of the tunnel parameter index.

\begin{tabular}{lc}
\hline Control index & Correlation degree \\
\hline Excavation method & 0.6639 \\
Blasting method & 0.5711 \\
Excavation section & 0.6261 \\
\hline
\end{tabular}

TABLE 19: Normalized eigenvectors of tunnel parameter index.

\begin{tabular}{lccc}
\hline Control index & Control index 1 & Control index 2 & Control index 3 \\
\hline X1 & 0.5201 & 0.7564 & -0.3967 \\
X2 & -0.5559 & 0.6524 & 0.5151 \\
X3 & 0.6484 & -0.0474 & 0.7598 \\
\hline
\end{tabular}

TABLE 20: Eigenvalues of tunnel parameter index.

\begin{tabular}{lccc}
\hline No. & Eigenvalue & Percentage (\%) & Cumulative percentage (\%) \\
\hline 1 & 1.8929 & 63.09 & 63.09 \\
2 & 0.7565 & 25.21 & 88.31 \\
3 & 0.3506 & 11.68 & 100 \\
\hline
\end{tabular}

Combined with the above gray correlation and principal component analyses, findings indicate that the optimal characteristic index of the method of initiation is the sequence of initiation.

(6) Tunnel parameters. X1-X3 represent the excavation method, blasting method, and excavation section, respectively. The correlation degree of tunnel parameter index calculated by gray correlation analysis is shown in Table 18 .

The above analysis shows that the first influencing factor of correlation degree is the excavation method, the second is the blasting method, and the third is the excavation section.

The normalized eigenvectors of the tunnel parameter indexes calculated by principal component analysis are shown in Table 19, and the eigenvalues are shown in Table 20.

Combined with the above analysis, findings indicate that the amount of information contained in the first two main components is $88.31 \%$ of the total amount of information, 
TABLE 21: Correlation degree of the construction factor index.

\begin{tabular}{lc}
\hline Control index & Correlation degree \\
\hline Drilling accuracy & 0.5910 \\
Measuring and setting out & 0.6499 \\
On-site management system & 0.6012 \\
\hline
\end{tabular}

TABLE 22: Normalized eigenvectors of construction factor index.

\begin{tabular}{lccc}
\hline Control index & Control index 1 & Control index 2 & Control index 3 \\
\hline X1 & 0.5837 & -0.5305 & 0.6147 \\
X2 & 0.6117 & -0.2105 & -0.7625 \\
X3 & 0.5339 & 0.8211 & 0.2017 \\
\hline
\end{tabular}

TABLE 23: Eigenvalues of construction factor index.

\begin{tabular}{lccc}
\hline No. & Eigenvalue & Percentage (\%) & Cumulative percentage (\%) \\
\hline 1 & 1.6548 & 55.15 & 55.15 \\
2 & 0.7474 & 24.91 & 80.07 \\
3 & 0.5978 & 19.92 & 100 \\
\hline
\end{tabular}

the first principal component represents $\mathrm{X} 3$, and the second principal component represents X1.

Combined with the above gray correlation and principal component analyses, findings indicate that the optimal characteristic index of tunnel parameters is the excavation method.

(7) Construction factors. X1-X3 represent the drilling accuracy, measuring and setting out, and on-site management system, respectively. The correlation degree of the construction factor index calculated by gray correlation analysis is shown in Table 21.

The above analysis shows that the first influencing factor of correlation degree is the measuring and setting out, the second is on-site management system, and the third is drilling accuracy.

The normalized eigenvectors of construction factor indexes calculated by principal component analysis are shown in Table 22, and the eigenvalues are shown in Table 23.

Combined with the above analysis, findings indicate that the amount of information contained in the first two main components is $80.07 \%$ of the total amount of information, the first principal component represents $\mathrm{X} 2$, and the second principal component represents X3.

Combined with the above gray correlation and principal component analyses, findings indicate that the optimal characteristic index of construction factor is the measuring and setting out.

2.4.3. Establishment of Quality Control Index System. In accordance with the primary selection and screening of the control index, abandoning the noncompliant index, the retaining control index is established according to the designed frame structure of the control system, and the tunnel smooth blasting quality control index system, which includes the seven criteria layers of geological conditions, explosive properties, borehole parameters, charge parameters, method of initiation, tunnel parameters, and construction factors, and a total of nine indexes, is established, as shown in Table 24.

\section{Results and Discussion}

On the basis of the comprehensive optimization control model of BP-ANN, ENN, and ANFIS, the following steps are used to adjust the subsequent blasting parameters to achieve quality control of tunnel smooth blasting.

(1) The measured tunnel smooth blasting data is used as a training sample of the neural network to establish an intelligent optimization model

(2) The uniform design method is used to optimize and adjust the blasting parameters of the tunnel section to be controlled, including the neighboring eyes spacing, the minimum resistance line, and linear charge density, and the parameter is adjusted locally and slightly mainly based on the actual blasting situation in the field, which primarily involves including upward adjustment (represented as "+"), downward adjustment (represented as “-”), and no adjustment (represented as "0"), and the adjustment range is selected from three levels, with a total of seven levels

(3) The optimized and adjusted smooth blasting parameter table data in step (2) are taken as a test sample of the comprehensive optimization model. The prediction results obtained by the comprehensive optimization control model are the tunnel smooth blasting quality index, which corresponds to the relevant level of each parameter

(4) The quality parameters of tunnel smooth blasting quality are evaluated by using the evaluation method established in the quality evaluation system of tunnel smooth blasting

(5) With the comprehensive index of tunnel smooth blasting quality taken as the standard, the obtained sets of parameters are sorted, and the optimal blasting parameter group is selected as the sample for tunnel smooth blasting quality control

(6) On the basis of the ANFIS and the ENN, comprehensive optimization control model is used to repeat steps (3)-(5). The two obtained tunnel smooth blasting quality control suggestions, together with the control suggestions obtained by the BP neural network, will be used as the suggested reference for design and construction personnel involved in the quality control of tunnel smooth blasting

Taking the Chengdu-Chongqing high-speed rail Da'an Tunnel as an example [32], three comprehensive optimization 
TABLE 24: Establishment of the quality control index system for tunnel smooth blasting.

\begin{tabular}{lcc}
\hline Control target layer & Control criterion layer & Control index layer (unit) \\
\hline & Geological conditions $B_{1}$ & Rock category $C_{11}$ \\
& Explosive properties $B_{2}$ & Blasting speed $C_{21}(\mathrm{~m} / \mathrm{s})$ \\
& Borehole parameters $B_{3}$ & Neighboring eyes spacing $C_{31}(\mathrm{~mm})$ \\
Quality control index system for tunnel smooth blasting $A$ & Restance line $C_{32}(\mathrm{~m})$ \\
& Charge parameters $B_{4}$ & Linear charge density $C_{41}(\mathrm{~kg} / \mathrm{m})$ \\
& Method of initiation $B_{5}$ & Sequence of initiation $C_{51}$ \\
& Tunnel parameters $B_{6}$ & Excavation method $C_{61}$ \\
& Construction factors $B_{7}$ & Measuring and setting out $C_{71}$ \\
\hline
\end{tabular}

control models were validated by using 34 sets of on-site obtained data (see Tables 25 and 26). First, these 34 sets of data were taken as the training samples of the comprehensive optimization control model. Nine control indexes, including the rock category, blasting speed, neighboring eyes spacing, and minimum resistance line in the tunnel smooth blasting quality control index system, were selected as inputs. Five evaluation indexes, including the maximum overbreak, maximum underbreak, and area of overbreak, were selected as outputs. To ensure the accuracy of the comprehensive optimization control model, the neural network structure of a double hidden layer (see Figure 23) was used, and the smooth blasting control parameters to be evaluated were grouped, with each group of a comprehensive optimization control neural network model including 9 inputs and 1 output. Then, the 34th set of data was selected as the test sample, and three constructed comprehensive optimization control models were used for testing to verify the accuracy of the test results and expected results. The prediction results of the three comprehensive optimization control models are compared in Table 27. Then, on the basis of the determined adjustment range of tunnel smooth blasting quality control parameters, the multifactor test was conducted by using a uniform design, which is based on the working condition of test factor level 7. The optimization scheme of tunnel smooth blasting quality control of seven test combinations was constructed (see Table 28). Otherwise, 343 tests must be conducted. Then, three comprehensive optimization control models were used to predict the established blasting optimization adjustment parameters. Finally, the conclusion of the prediction of the three prediction models was evaluated according to the index evaluation model constructed in the tunnel smooth blasting quality evaluation system to ensure the tunnel smooth blasting quality index of each control index, and it was sorted to determine the optimal smooth blasting quality control indexes and provide suggestions for tunnel smooth blasting quality control. The prediction results of BP-ANN, ENN, and ANFIS are shown in Tables 29-31.

As shown in Table 27, the ANFIS has the highest accuracy among the three comprehensive optimization control models; the maximum error is the maximum underbreak of
$0.059 \%$, and the minimum error is the area of overbreak and the blast hole utilization factor, which is $0.001 \%$. The ENN has a general accuracy; the maximum error is the maximum underbreak of $17.647 \%$, and the minimum error is the blast hole utilization factor, which is 0 . By contrast, the BPANN has poor accuracy; the maximum error is the volume of overbreak of $17.841 \%$, and the minimum error is the maximum underbreak, which is $1.588 \%$. The table also shows that when the tunnel smooth blasting quality is controlled and predicted by using the three constructed comprehensive optimization control models, the maximum and minimum errors of their respective predictions are not identical, thereby showing that these methods have their own advantages in the prediction and can complement each other. Thus, providing the control suggestions of the above three methods comprehensively are necessary, scientific, and feasible.

Table 29 shows that the sequence of the comprehensive quality index of tunnel smooth blasting of the seven designed schemes is as follows: scheme $7<$ scheme $6<$ scheme $2<$ scheme $4<$ scheme $3<$ scheme $5<$ scheme 1 , and the corresponding comprehensive quality index is as follows: 4.7826 $<4.9627<5.0385<5.0471<5.3801<5.6821<5.7305$. For its evaluation level, the other six scheme levels are intermediate, except the scheme 1 level is lower. Therefore, scheme 7 is the optimal one and can be used as the recommended control parameters, that is, the neighboring eyes spacing is not adjusted, the minimum resistance line is down-adjusted by $20 \%$, and the linear charge density is up-adjusted by $1 \%$. It is followed by scheme 6 , which can also be used as the recommended control parameters, that is, the neighboring eyes spacing is down-adjusted by $20 \%$, the minimum resistance line is down-adjusted by $15 \%$, and the linear charge density is down-adjusted by $1 \%$.

Table 30 shows that the sequence of the comprehensive quality index of tunnel smooth blasting of the seven designed schemes is as follows: scheme $6<$ scheme $7<$ scheme $2<$ scheme $4<$ scheme $1<$ scheme $3<$ scheme 5 , and the corresponding comprehensive quality index is successively as follows: $\quad 4.6670<4.6761<5.6525<5.9687<6.0994<6.4114$ $<6.8001$. The evaluation levels of schemes 2,6 , and 7 are intermediate, and the evaluation levels of the other three 
TABLE 25: Comprehensive optimization control model input training data.

\begin{tabular}{|c|c|c|c|c|c|c|c|c|c|}
\hline No. & $\begin{array}{c}\text { Rock } \\
\text { category }\end{array}$ & $\begin{array}{c}\text { Blasting } \\
\text { speed } \\
(\mathrm{m} / \mathrm{s})\end{array}$ & $\begin{array}{c}\text { Neighboring } \\
\text { eyes spacing } \\
(\mathrm{mm})\end{array}$ & $\begin{array}{c}\text { Minimum } \\
\text { resistance } \\
\text { line }(\mathrm{m})\end{array}$ & $\begin{array}{l}\text { Relative } \\
\text { distance }\end{array}$ & $\begin{array}{c}\text { Linear charge } \\
\text { density } \\
(\mathrm{kg} / \mathrm{m})\end{array}$ & $\begin{array}{c}\text { Sequence of } \\
\text { initiation }\end{array}$ & $\begin{array}{l}\text { Excavation } \\
\text { method }\end{array}$ & $\begin{array}{l}\text { Measuring and } \\
\text { setting out }\end{array}$ \\
\hline 1 & 0.3 & 3200 & 60 & 70 & 0.86 & 0.13 & 0.9 & 0.6 & 0.4 \\
\hline 2 & 0.3 & 3200 & 65 & 70 & 0.93 & 0.15 & 0.9 & 0.6 & 0.2 \\
\hline 3 & 0.3 & 3200 & 65 & 70 & 0.93 & 0.15 & 0.9 & 0.6 & 0.2 \\
\hline 4 & 0.3 & 3200 & 65 & 70 & 0.93 & 0.15 & 0.9 & 0.6 & 0.2 \\
\hline 5 & 0.3 & 3200 & 65 & 70 & 0.93 & 0.15 & 0.9 & 0.6 & 0.4 \\
\hline 6 & 0.3 & 3200 & 65 & 70 & 0.93 & 0.15 & 0.9 & 0.6 & 0.4 \\
\hline 7 & 0.3 & 3200 & 65 & 70 & 0.93 & 0.15 & 0.9 & 0.6 & 0.4 \\
\hline 8 & 0.5 & 3600 & 70 & 70 & 1 & 0.2 & 0.9 & 0.6 & 0.4 \\
\hline 9 & 0.5 & 3600 & 70 & 70 & 1 & 0.2 & 0.9 & 0.6 & 0.4 \\
\hline 10 & 0.5 & 3600 & 70 & 70 & 1 & 0.2 & 0.9 & 0.6 & 0.4 \\
\hline 11 & 0.5 & 3600 & 70 & 70 & 1 & 0.2 & 0.9 & 0.6 & 0.4 \\
\hline 12 & 0.5 & 3600 & 70 & 70 & 1 & 0.2 & 0.9 & 0.6 & 0.4 \\
\hline 13 & 0.3 & 3200 & 60 & 65 & 0.92 & 0.25 & 0.9 & 0.6 & 0.4 \\
\hline 14 & 0.3 & 3200 & 60 & 65 & 0.92 & 0.25 & 0.9 & 0.6 & 0.4 \\
\hline 15 & 0.3 & 3200 & 80 & 70 & 1.14 & 0.15 & 0.9 & 0.6 & 0.4 \\
\hline 16 & 0.5 & 4000 & 70 & 70 & 1 & 0.3 & 0.9 & 0.6 & 0.2 \\
\hline 17 & 0.5 & 4000 & 70 & 70 & 1 & 0.3 & 0.9 & 0.6 & 0.2 \\
\hline 18 & 0.5 & 4000 & 70 & 70 & 1 & 0.3 & 0.9 & 0.6 & 0.2 \\
\hline 19 & 0.5 & 4000 & 70 & 70 & 1 & 0.3 & 0.9 & 0.6 & 0.2 \\
\hline 20 & 0.5 & 3200 & 60 & 65 & 0.92 & 0.15 & 0.9 & 0.6 & 0.2 \\
\hline 21 & 0.5 & 3200 & 60 & 65 & 0.92 & 0.15 & 0.9 & 0.6 & 0.2 \\
\hline 22 & 0.5 & 3200 & 60 & 65 & 0.92 & 0.15 & 0.9 & 0.6 & 0.2 \\
\hline 23 & 0.5 & 3200 & 60 & 65 & 0.92 & 0.15 & 0.9 & 0.6 & 0.2 \\
\hline 24 & 0.5 & 3200 & 60 & 65 & 0.92 & 0.15 & 0.9 & 0.6 & 0.2 \\
\hline 25 & 0.5 & 3200 & 60 & 65 & 0.92 & 0.15 & 0.9 & 0.6 & 0.2 \\
\hline 26 & 0.5 & 3200 & 60 & 65 & 0.92 & 0.15 & 0.9 & 0.6 & 0.2 \\
\hline 27 & 0.5 & 3200 & 60 & 60 & 1 & 0.25 & 0.9 & 0.6 & 0.2 \\
\hline 28 & 0.5 & 3200 & 60 & 60 & 1 & 0.25 & 0.9 & 0.6 & 0.2 \\
\hline 29 & 0.5 & 3200 & 60 & 60 & 1 & 0.25 & 0.9 & 0.6 & 0.2 \\
\hline 30 & 0.3 & 4200 & 65 & 70 & 0.93 & 0.3 & 0.9 & 0.6 & 0.2 \\
\hline 31 & 0.3 & 4200 & 65 & 70 & 0.93 & 0.3 & 0.9 & 0.6 & 0.2 \\
\hline 32 & 0.3 & 4200 & 65 & 70 & 0.93 & 0.45 & 0.9 & 0.6 & 0.2 \\
\hline 33 & 0.3 & 4200 & 60 & 70 & 0.86 & 0.4 & 0.9 & 0.6 & 0.4 \\
\hline 34 & 0.3 & 4200 & 60 & 70 & 0.86 & 0.15 & 0.9 & 0.6 & 0.4 \\
\hline
\end{tabular}

schemes are lower. Therefore, scheme 6 is the optimal scheme, which can be used as the recommended control parameters, that is, the neighboring eyes spacing is down-adjusted by $20 \%$, the minimum resistance line is down-adjusted by $15 \%$, and the linear charge density is down-adjusted by $1 \%$. It is followed by scheme 7 , which can also be used as the recommended control parameters, that is, the neighboring eyes spacing is not adjusted, the minimum resistance line is down-adjusted by $20 \%$, and the linear charge density is upadjusted by $1 \%$.

Table 31 shows that the sequence of the comprehensive quality index of tunnel smooth blasting of seven designed schemes is as follows: scheme $6<$ scheme $7<$ scheme $1<$ scheme $3<$ scheme $5<$ scheme $2<$ scheme 4 , and the corresponding comprehensive quality index is as follows: 4.0784 $<4.2872<5.0550<6.2411<6.5827<7.0089<8.1479$. The evaluation level of scheme 1 is better, the evaluation levels of schemes 6 and 7 are intermediate, and the evaluation levels of schemes 2, 3, and 5 are lower. Therefore, scheme 6 is the optimal scheme and can be used as the recommended control parameters, that is, the neighboring eyes spacing is down-adjusted by $20 \%$, the minimum resistance line is down-adjusted by $15 \%$, and the linear charge density is down-adjusted by $1 \%$. It is followed by scheme 7 , which can also be used as the recommended control parameters, that is, the neighboring eyes spacing is not adjusted, the 
TABLE 26: Comprehensive optimization control model output training data.

\begin{tabular}{|c|c|c|c|c|c|}
\hline No. & $\begin{array}{l}\text { Maximum overbreak } \\
(\mathrm{m})\end{array}$ & $\begin{array}{l}\text { Maximum underbreak } \\
(\mathrm{m})\end{array}$ & $\begin{array}{c}\text { Area of overbreak } \\
\left(\mathrm{m}^{2}\right)\end{array}$ & $\begin{array}{l}\text { Volume of overbreak } \\
\qquad\left(\mathrm{m}^{3}\right)\end{array}$ & $\begin{array}{c}\text { Blast hole utilization factor } \\
(\%)\end{array}$ \\
\hline 1 & 0.81 & 0.23 & 10.4 & 10.4 & 79 \\
\hline 2 & 0.7 & 0.68 & 7.78 & 7.78 & 92 \\
\hline 3 & 0.73 & 0.04 & 10.91 & 5.46 & 84 \\
\hline 4 & 0.85 & 0.04 & 9.64 & 4.82 & 84 \\
\hline 5 & 0.65 & 0.02 & 7.69 & 3.85 & 95 \\
\hline 6 & 0.78 & 0.41 & 6.03 & 9.05 & 89 \\
\hline 7 & 0.66 & 0.24 & 7.52 & 3.76 & 89 \\
\hline 8 & 0.57 & 0.08 & 7.98 & 3.99 & 89 \\
\hline 9 & 0.64 & 0.14 & 11.78 & 5.89 & 95 \\
\hline 10 & 0.8 & 0.14 & 12.63 & 3.79 & 95 \\
\hline 11 & 0.78 & 0.26 & 12.17 & 2.43 & 95 \\
\hline 12 & 0.73 & 0.11 & 10.16 & 5.08 & 95 \\
\hline 13 & 0.56 & 0.03 & 9.88 & 4.94 & 95 \\
\hline 14 & 0.66 & 0.13 & 9.62 & 0.96 & 84 \\
\hline 15 & 0.98 & 0.21 & 13.91 & 4.17 & 92 \\
\hline 16 & 0.6 & 0.1 & 8.67 & 2.6 & 95 \\
\hline 17 & 0.52 & 0.07 & 7.74 & 1.55 & 95 \\
\hline 18 & 0.7 & 0.1 & 7.48 & 3.74 & 95 \\
\hline 19 & 0.74 & 0.05 & 8.89 & 4.45 & 95 \\
\hline 20 & 0.85 & 0.01 & 10.63 & 5.32 & 95 \\
\hline 21 & 0.58 & 0.19 & 6.09 & 3.05 & 92 \\
\hline 22 & 0.78 & 0.03 & 12.43 & 3.73 & 92 \\
\hline 23 & 0.75 & 0.07 & 12.92 & 2.58 & 92 \\
\hline 24 & 0.59 & 0.03 & 10.9 & 5.45 & 92 \\
\hline 25 & 0.69 & 0.28 & 4.7 & 2.35 & 79 \\
\hline 26 & 0.58 & 0.02 & 9.46 & 2.84 & 79 \\
\hline 27 & 0.88 & 0.04 & 9 & 4.5 & 79 \\
\hline 28 & 0.91 & 0.33 & 8.58 & 4.29 & 84 \\
\hline 29 & 0.86 & 0.26 & 10.97 & 5.49 & 84 \\
\hline 30 & 0.71 & 0.34 & 6.85 & 3.43 & 87 \\
\hline 31 & 0.61 & 0.09 & 9.97 & 4.99 & 87 \\
\hline 32 & 0.45 & 0.14 & 5.63 & 2.82 & 87 \\
\hline 33 & 0.49 & 0.15 & 6.61 & 3.31 & 87 \\
\hline 34 & 0.73 & 0.17 & 8.92 & 4.46 & 82 \\
\hline
\end{tabular}

minimum resistance line is down-adjusted by $20 \%$, and the linear charge density is up-adjusted by $1 \%$;

To further analyze the advantages of the BP-ANN, the ENN, and the ANFIS in the application of tunnel smooth blasting quality control, the corresponding optimal scheme and the better scheme are compared.

Table 32 shows that, among the three comprehensive optimization control models, the comprehensive quality index accuracy given by the ANFIS prediction is the highest; the proposed control scheme is more reliable, followed by the ENN, and then the BP-ANN. After comprehensive optimization, the optimal recommendation control scheme given by the ANFIS and ENN is scheme 6, and the optimal control scheme is scheme 7 , which proceeds is as follows: the neigh- boring eyes spacing is down-adjusted by $20 \%$, the minimum resistance line is down-adjusted by $15 \%$, and the linear charge density is down-adjusted by $1 \%$. In the better scheme, the neighboring eyes spacing is not adjusted, the minimum resistance line is down-adjusted by $20 \%$, and the linear charge density is up-adjusted by $1 \%$. In addition, the control scheme obtained by BP-ANN optimization is opposite to the optimal and better control scheme obtained by ANFIS and ENN optimization. Thus, the above three comprehensive optimization models can complement each other in controlling tunnel smooth blasting, and the field tunnel duty engineer can perform appropriate adjustment of the tunnel blasting parameters according to the actual situation of blasting, combined with the obtained blasting control, to ensure 


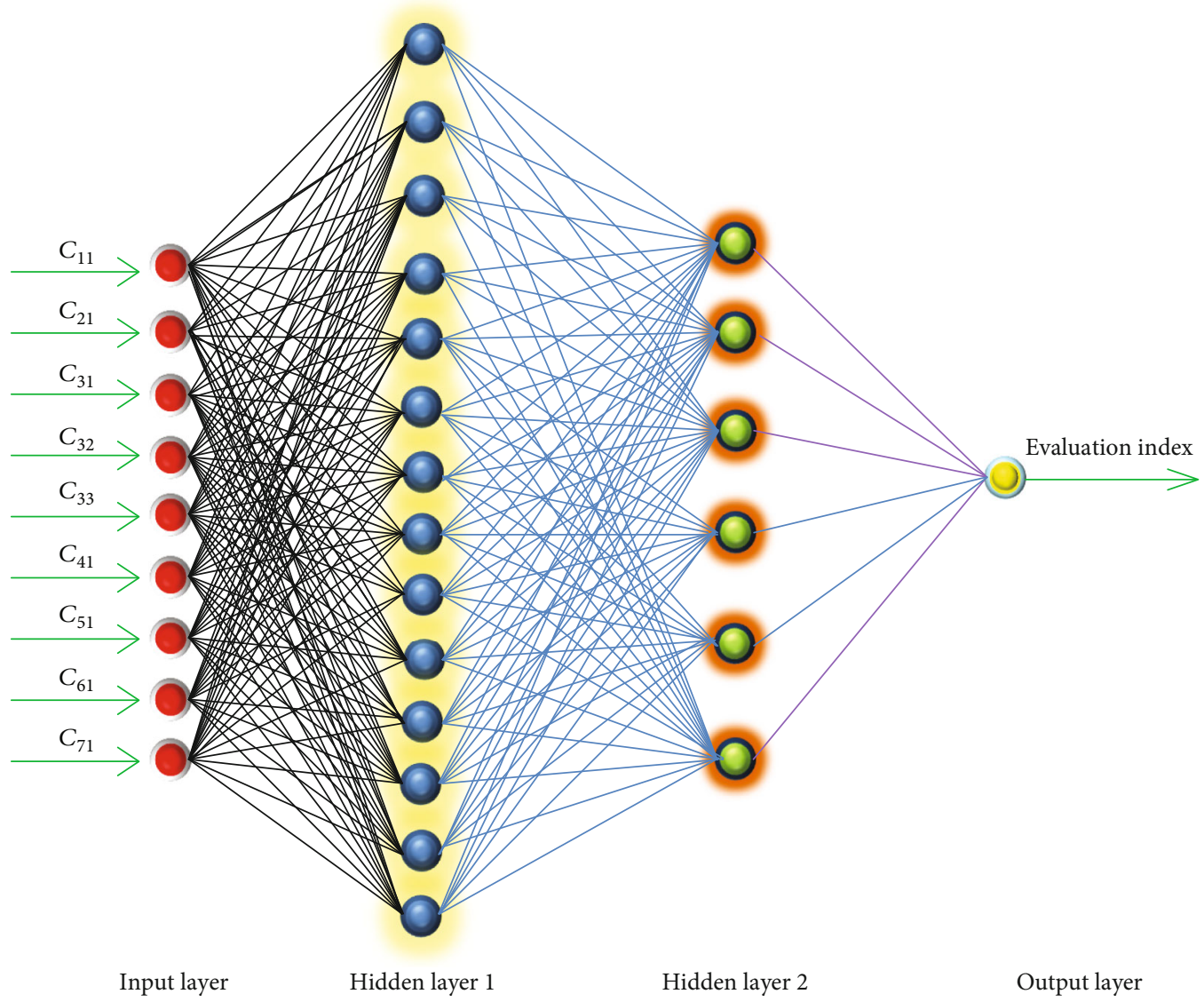

Figure 23: Neural network structure of synthetically optimized control model.

TABLE 27: Comparison of prediction results of three comprehensive optimization control models.

\begin{tabular}{|c|c|c|c|c|c|c|c|}
\hline \multirow{2}{*}{ Evaluation index } & \multicolumn{3}{|c|}{ Actual output } & \multirow{2}{*}{ Desired output } & \multicolumn{3}{|c|}{ Error (\%) } \\
\hline & BP-ANN & ENN & ANFIS & & BP-ANN & ENN & ANFIS \\
\hline Maximum overbreak (m) & 0.750 & 0.700 & 0.730 & 0.73 & 2.730 & 4.110 & 0.014 \\
\hline Maximum underbreak (m) & 0.173 & 0.200 & 0.170 & 0.17 & 1.588 & 17.647 & 0.059 \\
\hline Area of overbreak $\left(\mathrm{m}^{2}\right)$ & 7.734 & 9.000 & 8.920 & 8.92 & 13.291 & 0.897 & 0.001 \\
\hline Volume of overbreak $\left(\mathrm{m}^{3}\right)$ & 5.256 & 4.000 & 4.460 & 4.46 & 17.841 & 10.314 & 0.002 \\
\hline Blast hole utilization factor (\%) & 87.519 & 82.000 & 81.999 & 82.00 & 6.731 & 0 & 0.001 \\
\hline
\end{tabular}

TABLE 28: Optimization scheme of tunnel smooth blasting quality control.

\begin{tabular}{lccc}
\hline Scheme & $\begin{array}{c}\text { Neighboring eyes } \\
\text { spacing }\end{array}$ & $\begin{array}{c}\text { Minimum } \\
\text { resistance line }\end{array}$ & $\begin{array}{c}\text { Linear charge } \\
\text { density }\end{array}$ \\
\hline 1 & $+10 \%$ & $+20 \%$ & 0 \\
2 & $+15 \%$ & $-10 \%$ & $+3 \%$ \\
3 & $-10 \%$ & 0 & $-3 \%$ \\
4 & $+20 \%$ & $+10 \%$ & $-2 \%$ \\
5 & $-15 \%$ & $+15 \%$ & $+2 \%$ \\
6 & $-20 \%$ & $-15 \%$ & $-1 \%$ \\
7 & 0 & $-20 \%$ & $+1 \%$ \\
\hline
\end{tabular}

that the tunnel blasting molding is regular and meets the requirements of the design contour line, guaranteeing the safe construction of the tunnel.

\section{Conclusion}

(1) This paper presents a method of constructing the tunnel smooth blasting quality control index system and establishes a tunnel smooth blasting quality control index system with seven criteria layers of geological conditions, explosive properties, borehole parameters, charge parameters, method of initiation, tunnel parameters, and construction factors, and a total of nine indexes 
TABLE 29: Prediction and calculation results of BP-ANN.

\begin{tabular}{lcccccccc}
\hline Scheme & $\begin{array}{c}\text { Maximum } \\
\text { overbreak } \\
(\mathrm{m})\end{array}$ & $\begin{array}{c}\text { Maximum } \\
\text { underbreak } \\
(\mathrm{m})\end{array}$ & $\begin{array}{c}\text { Area of } \\
\text { overbreak } \\
\left(\mathrm{m}^{2}\right)\end{array}$ & $\begin{array}{c}\text { Volume of } \\
\text { overbreak } \\
\left(\mathrm{m}^{3}\right)\end{array}$ & $\begin{array}{c}\text { Blast hole } \\
\text { utilization } \\
\text { factor }(\%)\end{array}$ & $\begin{array}{c}\text { Comprehensive } \\
\text { quality index }\end{array}$ & $\begin{array}{c}\text { Ranking } \\
\text { levels }\end{array}$ & $\begin{array}{c}\text { Evaluation } \\
\text { inder }\end{array}$ \\
\hline 1 & 0.73321 & 0.14068 & 7.6426 & 2.0493 & 91.8955 & 5.7305 & 7 & 3 \\
2 & 0.5238 & 0.20529 & 6.2971 & 4.7621 & 94.529 & 5.0385 & Intermediate \\
3 & 0.59019 & 0.16555 & 5.3813 & 4.2713 & 84.7194 & 5.0471 & 4 & Intermediate \\
4 & 0.66531 & 0.17023 & 7.4979 & 5.2137 & 90.2135 & 5.3801 & 5 & Intermediate \\
5 & 0.60658 & 0.13424 & 7.7708 & 5.1349 & 85.2039 & 5.6821 & 6 & Intermediate \\
6 & 0.68356 & 0.13295 & 7.4522 & 2.1966 & 91.9912 & 4.9627 & 2 & Intermediate \\
7 & 0.66945 & 0.0829 & 7.1015 & 4.6401 & 90.9793 & 4.7826 & 1 & Intermediate \\
\hline
\end{tabular}

TABLE 30: Prediction and calculation results of ENN.

\begin{tabular}{lcccccccc}
\hline Scheme & $\begin{array}{c}\text { Maximum } \\
\text { overbreak } \\
(\mathrm{m})\end{array}$ & $\begin{array}{c}\text { Maximum } \\
\text { underbreak } \\
(\mathrm{m})\end{array}$ & $\begin{array}{c}\text { Area of } \\
\text { overbreak } \\
\left(\mathrm{m}^{2}\right)\end{array}$ & $\begin{array}{c}\text { Volume of } \\
\text { overbreak } \\
\left(\mathrm{m}^{3}\right)\end{array}$ & $\begin{array}{c}\text { Blast hole } \\
\text { utilization } \\
\text { factor }(\%)\end{array}$ & $\begin{array}{c}\text { Comprehensive } \\
\text { quality index }\end{array}$ & $\begin{array}{c}\text { Ranking } \\
\text { Evaluation } \\
\text { levels }\end{array}$ \\
\hline 1 & 0.60 & 0.2 & 8.00 & 6.00 & 87.00 & 6.0994 & 5 & Lower \\
2 & 0.70 & 0.1 & 11.00 & 2.00 & 81.00 & 5.6525 & 3 & Intermediate \\
3 & 0.80 & 0.1 & 10.00 & 5.00 & 82.00 & 6.4114 & 6 & Lower \\
4 & 0.70 & 0.3 & 5.00 & 7.00 & 92.00 & 5.9687 & 4 & Lower \\
5 & 0.80 & 0.2 & 8.00 & 5.00 & 76.00 & 6.8001 & 7 & Lower \\
6 & 0.60 & 0.1 & 5.00 & 4.00 & 78.00 & 4.6670 & 1 & Intermediate \\
7 & 0.6 & 0.1 & 11.00 & 1.00 & 87.00 & 4.6761 & 2 & Intermediate \\
\hline
\end{tabular}

TABLE 31: Prediction and calculation results of ANFIS.

\begin{tabular}{lcccccccc}
\hline Scheme & $\begin{array}{c}\text { Maximum } \\
\text { overbreak } \\
(\mathrm{m})\end{array}$ & $\begin{array}{c}\text { Maximum } \\
\text { underbreak } \\
(\mathrm{m})\end{array}$ & $\begin{array}{c}\text { Area of } \\
\text { overbreak } \\
\left(\mathrm{m}^{2}\right)\end{array}$ & $\begin{array}{c}\text { Volume of } \\
\text { overbreak } \\
\left(\mathrm{m}^{3}\right)\end{array}$ & $\begin{array}{c}\text { Blast hole } \\
\text { utilization } \\
\text { factor }(\%)\end{array}$ & $\begin{array}{c}\text { Comprehensive } \\
\text { quality index }\end{array}$ & $\begin{array}{c}\text { Ranking } \\
\text { Evaluation } \\
\text { levels }\end{array}$ \\
\hline 1 & 0.65179 & 0.04237 & 11.2666 & 2.3705 & 83.8092 & 5.0550 & 3 & Intermediate \\
2 & 0.7501 & 0.19015 & 9.1208 & 4.6613 & 82.1939 & 7.0089 & 6 & Lower \\
3 & 0.67107 & 0.11091 & 8.3311 & 3.8699 & 81.4316 & 6.2411 & 4 & Lower \\
4 & 0.91053 & 0.3484 & 10.7848 & 6.1676 & 85.0023 & 8.1479 & 7 & Very poor \\
5 & 0.74423 & 0.18423 & 9.0631 & 4.6009 & 82.1572 & 6.5827 & 5 & Lower \\
6 & 0.50991 & 0.05068 & 6.7208 & 2.2561 & 79.8776 & 4.0784 & 1 & Better \\
7 & 0.59349 & 0.03313 & 7.556 & 3.0931 & 80.6837 & 4.2872 & 2 & Intermediate \\
\hline
\end{tabular}

TABLE 32: Comparison of the optimal scheme and the better scheme of three comprehensive optimization control models.

\begin{tabular}{lcccc}
\hline Comprehensive optimization control model & Scheme & Comprehensive quality index & Scheme sequence & Evaluation level \\
\hline \multirow{2}{*}{ BP-ANN } & 7 & 4.7826 & 1 & 2 \\
& 6 & 4.9627 & 1 & Intermediate \\
\multirow{2}{*}{ ENN } & 6 & 4.667 & 2 & Intermediate \\
\hline \multirow{2}{*}{ ANFIS } & 7 & 4.6761 & 1 & Intermediate \\
& 7 & 4.0784 & 2 & Bntermediate \\
\hline
\end{tabular}

(2) The comprehensive optimization control models of BP-ANN, ANFIS, and ENN for tunnel smooth blasting quality are established. The established models can provide real-time, accurate, and objective control suggestions and control values of tunnel smooth blasting quality, can quickly optimize and adjust the tunnel smooth blasting parameters according to the evaluation level of tunnel smooth blasting quality, 
and change the postcontrol of smooth blasting quality to precontrol

(3) Taking the Chengdu-Chongqing high-speed rail Da'an Tunnel as the background, the blasting parameters of the tunnel section that needs to be controlled are optimized and adjusted by using the uniform design method to verify the practicability and correctness of the comprehensive optimization control model of the BP-ANN, ANFIS, and ENN. Results show that the comprehensive optimization control models can change the focus of tunnel smooth blasting quality control from the traditional single index control method to a dynamic, intelligent, pluralistic, and integrated control technology

\section{Data Availability}

The data are available and explained in this article; readers can access the data supporting the conclusions of this study.

\section{Conflicts of Interest}

The authors declare that there is no conflict of interests regarding the publication of this paper.

\section{Acknowledgments}

The financial supports for this research project by the National Natural Science Foundation of China (No. 41602308, 41572299), the Zhejiang Provincial Natural Science Foundation of China (No. LY20E080005), the graduate teaching reform research project of Zhejiang University of Science and Technology (Grant No. 2019yjsjg01), the Zhejiang Science and Technology Project (No. 2016C33033), and the Foundation of China Railway No.2 Engineering Group Co., Ltd. (No. 201218) are all gratefully acknowledged.

\section{References}

[1] G. M. Foderà, A. Voza, G. Barovero, F. Tinti, and D. Boldini, "Factors influencing overbreak volumes in drill-and-blast tunnel excavation. A statistical analysis applied to the case study of the Brenner Base Tunnel - BBT," Tunnelling and Underground Space Technology, vol. 105, article 103475, 2020.

[2] X. Huo, X. Shi, X. Qiu et al., "Rock damage control for largediameter-hole lateral blasting excavation based on charge structure optimization," Tunnelling and Underground Space Technology, vol. 106, article 103569, 2020.

[3] S. Zare and A. Bruland, "Comparison of tunnel blast design models," Tunnelling and Underground Space Technology, vol. 21, no. 5, pp. 533-541, 2006.

[4] T. Ghara, S. Paul, and P. Bandyopadhyay, "Effect of grit blasting parameters on surface and near-surface properties of different metal alloys," Journal of Thermal Spray Technology, 2020.

[5] Y. Kim and H.-K. Moon, "Application of the guideline for overbreak control in granitic rock masses in Korean tunnels," Tunnelling and Underground Space Technology, vol. 35, pp. $67-77,2013$.
[6] N. H. Maerz, J. A. Ibarra, and J. A. Franklin, "Overbreak and underbreak in underground openings part 1: measurement using the light sectioning method and digital image processing," Geotechnical and Geological Engineering, vol. 14, no. 4, pp. 307-323, 1996.

[7] J. A. Franklin, N. H. Maerz, and J. A. Ibarra, "Overbreak and underbreak in underground openings part 2: causes and implications," Geotechnical and Geological Engineering, vol. 14, no. 4, pp. 325-340, 1996.

[8] A. Mortazavi and P. D. Katsabanis, "Modelling burden size and strata dip effects on the surface blasting process," International Journal of Rock Mechanics and Mining Sciences, vol. 38, no. 4, pp. 481-498, 2001.

[9] S. H. Cho, Y. Nakamura, B. Mohanty, H. S. Yang, and K. Kaneko, "Numerical study of fracture plane control in laboratory-scale blasting," Engineering Fracture Mechanics, vol. 75, no. 13, pp. 3966-3984, 2008.

[10] C. Li, L. Kang, Q. Qi, D. Mao, Q. Liu, and G. Xu, "The numerical analysis of borehole blasting and application in coal mine roof-weaken," Procedia Earth and Planetary Science, vol. 1, no. 1, pp. 451-459, 2009.

[11] Z. Zhu, "Numerical prediction of crater blasting and bench blasting," International Journal of Rock Mechanics and Mining Sciences, vol. 46, no. 6, pp. 1088-1096, 2009.

[12] X. Li, Y. Long, C. Ji, and M. Zhong, "Study on the vibration effect on operation subway induced by blasting of an adjacent cross tunnel and the reducing vibration techniques," Journal of Vibroengineering, vol. 15, no. 3, pp. 1454-1462, 2013.

[13] M. Kamali and M. Ataei, "Prediction of blast induced ground vibrations in Karoun III power plant and dam: a neural network," Journal of the South African Institute of Mining and Metallurgy, vol. 110, no. 8, pp. 481-490, 2010.

[14] H. Jang and E. Topal, "Optimizing overbreak prediction based on geological parameters comparing multiple regression analysis and artificial neural network," Tunnelling and Underground Space Technology, vol. 38, pp. 161-169, 2013.

[15] G.-H. Zhang, W. Chen, Y.-Y. Jiao, H. Wang, and C.-T. Wang, "A failure probability evaluation method for collapse of drilland-blast tunnels based on multistate fuzzy Bayesian network," Engineering Geology, vol. 276, article 105752, 2020.

[16] Q. Meng, H. Wang, M. Cai, W. Xu, X. Zhuang, and T. Rabczuk, "Three-dimensional mesoscale computational modeling of soil-rock mixtures with concave particles," Engineering Geology, vol. 277, article 105802, 2020.

[17] G. Xu and C. Yan, "Numerical simulation for influence of excavation and blasting vibration on stability of mined-out area," Journal of Central South University of Technology, vol. 13, no. 5, pp. 577-583, 2006.

[18] V. Isheyskiy and J. A. Sanchidrian, "Prospects of applying mwd technology for quality management of drilling and blasting operations at mining enterprises," Minerals, vol. 10, no. 10, p. $925,2020$.

[19] G. Liu, X. Feng, G. Feng, B. Chen, D. Chen, and S. Duan, “A method for dynamic risk assessment and management of rockbursts in drill and blast tunnels," Rock Mechanics and Rock Engineering, vol. 49, no. 8, pp. 3257-3279, 2016.

[20] S. Fekete, M. Diederichs, and M. Lato, "Geotechnical and operational applications for 3-dimensional laser scanning in drill and blast tunnels," Tunnelling and Underground Space Technology, vol. 25, no. 5, pp. 614-628, 2010. 
[21] J. Hao, Y. Lin, G. Ren et al., "Comprehensive benefit evaluation of conservation tillage based on BP neural network in the Loess Plateau," Soil and Tillage Research, vol. 205, article 104784, 2021.

[22] C. Ren, N. An, J. Wang, L. Li, B. Hu, and D. Shang, "Optimal parameters selection for BP neural network based on particle swarm optimization: a case study of wind speed forecasting," Knowledge-Based Systems, vol. 56, pp. 226-239, 2014.

[23] L. Yang, F. Wang, J. Zhang, and W. Ren, "Remaining useful life prediction of ultrasonic motor based on Elman neural network with improved particle swarm optimization," Measurement, vol. 143, pp. 27-38, 2019.

[24] D. Yu, Y. Wang, H. Liu, K. Jermsittiparsert, and N. Razmjooy, "System identification of PEM fuel cells using an improved Elman neural network and a new hybrid optimization algorithm," Energy Reports, vol. 5, pp. 1365-1374, 2019.

[25] M. Motahari-Nezhad and S. M. Jafari, "ANFIS system for prognosis of dynamometer high-speed ball bearing based on frequency domain acoustic emission signals," Measurement, vol. 166, article 108154, 2020.

[26] A. Boga, M. Ozturk, and I. Topcu, "Using ANN and ANFIS to predict the mechanical and chloride permeability properties of concrete containing GGBFS and CNI," Composites Part BEngineering, vol. 45, no. 1, pp. 688-696, 2013.

[27] Q. Li, S. Chen, and R. Zhao, "Study on evaluation of timber security in china based on the PSR conceptual model," Forests, vol. 11, no. 5, p. 517, 2020.

[28] D. Zhou, Z. Lin, L. Liu, and D. Zimmermann, "Assessing secondary soil salinization risk based on the PSR sustainability framework," Journal of Environmental Management, vol. 128, pp. 642-654, 2013.

[29] D. Zhang, J. Shen, P. Liu, and F. Sun, "Allocation of flood drainage rights based on the PSR model and pythagoras fuzzy topsis method," International Journal of Environmental Research and Public Health, vol. 17, no. 16, article 5821, 2020.

[30] C. Zheng, R. Li, M. Hu, and L. Zou, "Determination of lowtemperature crack control parameter of binding asphalt materials based on gray correlation analysis," Construction and Building Materials, vol. 217, pp. 226-233, 2019.

[31] L. Peng, G. Han, A. L. Pagou, and J. Shu, "Electric submersible pump broken shaft fault diagnosis based on principal component analysis," Journal of Petroleum Science and Engineering, vol. 191, article 107154, 2020.

[32] B. Zou, Z. Xu, J. Wang, Z. Luo, and L. Hu, "Numerical investigation on influential factors for quality of smooth blasting in rock tunnels," Advances in Civil Engineering, vol. 2020, Article ID 9854313, 17 pages, 2020.

[33] Z. Zhao, Y. Zhang, and H. Bao, "Tunnel blasting simulations by the discontinuous deformation analysis," International Journal of Computational Methods, vol. 8, no. 2, pp. 277-292, 2011.

[34] G. Adhikari, A. Rajan Babu, R. Balachander, and R. Gupta, "On the application of rock mass quality for blasting in large underground chambers," Tunnelling and Underground Space Technology, vol. 14, no. 3, pp. 367-375, 1999.

[35] S. Paul Singh and P. Xavier, "Causes, impact and control of overbreak in underground excavations," Tunnelling and Underground Space Technology, vol. 20, no. 1, pp. 63-71, 2005.

[36] K. Dey and V. Murthy, "Prediction of blast-induced overbreak from uncontrolled burn-cut blasting in tunnels driven through medium rock class," Tunnelling and Underground Space Technology, vol. 28, pp. 49-56, 2012.

[37] G. Henning and H. Mitri, "Numerical modelling of ore dilution in blasthole stoping," International Journal of Rock Mechanics and Mining Sciences, vol. 44, no. 5, pp. 692-703, 2007.

[38] C. Kuzu and E. Guclu, "The problem of human response to blast induced vibrations in tunnel construction and mitigation of vibration effects using cautious blasting in half-face blasting rounds," Tunnelling and Underground Space Technology, vol. 24, no. 1, pp. 53-61, 2009.

[39] Z. Li, H. Liu, Z. Dun, L. Ren, and J. Fang, "Grouting effect on rock fracture using shear and seepage assessment," Construction and Building Materials, vol. 242, article 118131, 2020.

[40] Z. Li, S. Liu, W. Ren, J. Fang, Q. Zhu, and Z. Dun, "Multiscale laboratory study and numerical analysis of water-weakening effect on shale," Advances in Materials Science and Engineering, vol. 2020, Article ID 5263431, 2020.

[41] C. Zhu, M. He, M. Karakus, X. Cui, and Z. Tao, "Investigating toppling failure mechanism of anti-dip layered slope due to excavation by physical modelling," Rock Mechanics and Rock Engineering, vol. 53, no. 11, pp. 5029-5050, 2020.

[42] C. Zhu, X. Xu, W. Liu et al., "Softening damage analysis of gypsum rock with water immersion time based on laboratory experiment," IEEE Access, vol. 7, pp. 125575-125585, 2019.

[43] C. Zhu, Z. Yan, Y. Lin, F. Xiong, and Z. Tao, "Design and application of a monitoring system for a deep railway foundation pit project," IEEE Access, vol. 7, pp. 107591-107601, 2019.

[44] L. Yang, W. Xu, Q. Meng, and R. Wang, "Investigation on jointed rock strength based on fractal theory," Journal of Central South University, vol. 24, no. 7, pp. 1619-1626, 2017.

[45] Q. X. Meng, L. Yan, Y. L. Chen, and Q. Zhang, "Generation of numerical models of anisotropic columnar jointed rock mass using modified centroidal voronoi diagrams," Symmetry, vol. 10, no. 11, p. 618, 2018.

[46] Q. X. Meng and W. Wang, "A novel closed-form solution for circular openings in generalized Hoek-Brown media," Mathematical Problems in Engineering, vol. 2014, Article ID 870835, 7 pages, 2014.

[47] W. Wang, L. Q. Li, W. Y. Xu, Q. X. Meng, and J. Lv, "Creep failure mode and criterion of Xiangjiaba sandstone," Journal of Central South University, vol. 19, no. 12, pp. 3572-3581, 2012.

[48] C. Shi, S. N. Wang, L. Liu, Q. X. Meng, and Q. Zhang, "Mesomechanical simulation of direct shear test on outwash deposits with granular discrete element method," Journal of Central South University, vol. 20, no. 4, pp. 1094-1102, 2013. 